\title{
A High-Efficiency Energy Harvesting By Using Hydraulic Electromagnetic Regenerative Shock Absorber
}

Muhammad Yousaf Iqbal ( $\sim$ yousaf801@163.com)

Taiyuan University of Science and Technology https://orcid.org/0000-0003-0047-9755

Zhifei Wu

Taiyuan University

Khalid Mahmood

Beijing University of Chinese Medicine

\section{Original Article}

Keywords: Energy Harvesting, Damping Characteristics Curves, AMESim Simulation, HESA

Posted Date: June 16th, 2020

DOl: https://doi.org/10.21203/rs.3.rs-34207/v1

License: (c) (i) This work is licensed under a Creative Commons Attribution 4.0 International License.

Read Full License 


\title{
Article
}

\section{A High-Efficiency Energy Harvesting By Using Hydraulic Electromagnetic Regenerative Shock Absorber}

\author{
Muhammad Yousaf Iqbal 1,* Zhifei Wu 2,Khalid2 \\ 1 Taiyuan University of Technology Shanxi China, yousaf804@163.com (M.Y.I) \\ 2 Taiyuan University of Technology Shanxi China, yousaf804@163.com (M.Y.I) \\ * Correspondence: yousaf804@163.com; Tel.: +8615535174094(M.Y.I)
}

\begin{abstract}
This article intends a hybrid energy harvesting shock absorber design which comprehends energy harvesting of automobile suspension vibration dissipation. A mathematical model of the energy harvesting prototype is established, and simulation results show that the dissipation energy can be recovered by varying the feed module, thereby got the damping forces ratio at different compression and extension stroke. The energy conversion from hydraulic energy to mechanical energy mainly then mechanical energy converted into electrical energy furthermore we can rechange our battery from this recovered energy. The advanced mathematical model and prototype proposed maximum ride comfort meanwhile recovered the suspension energy and fuel saving. This article shows the simulation results verifying it with prototype test results. The damping force of expansion stroke is higher than the damping force of compression stroke. The damping characteristics curves and speed characteristics curves verify the validity by simulation and prototyping damper at different amplitudes of off-road vehicles. The Hydraulic Electromagnetic Regenerative Shock Absorber (HESA) prototype characteristic is tested in which 65 watts recovered energy at $1.67 \mathrm{~Hz}$ excitation frequency. So, $14.65 \%$ maximum energy recovery efficiency got at $20 \mathrm{~mm}$ rod diameter and $8 \mathrm{cc} / \mathrm{rev}$ motor displacement. The damping characteristics of the HESA prototype examined and it has ideal performance as the standard requirements of the National Standard QC/T 491-1999.
\end{abstract}

Key Words: Energy Harvesting, Damping Characteristics Curves, AMESim Simulation, HESA,

\section{Introduction}

The suspension plays a vital role in vehicles, especially to satisfy ride comfort and road performance. The improvement of regenerative shock absorber has been extensively conducted. The energy crisis increase has become a major factor in vehicles. The vibrational energy of the vehicles is dissipated by the shocks. From the last two decades, researchers are trying to harvest that wasted energy and converting into electricity. By harvesting the suspension energy the fuel consumption would be decreased and can save a million dollars. These conditions put pressure on electrical appliances [1]. Renewable energy has found great success in hybrid cars. In addition, the fuel economy should reduce air pollution. It is estimated that only " $10-16 \%$ of the total energy is used to overcome road friction and air drag"[2]. The handling stability, the excellent performance of the energy-feed suspension and the huge research potential make it in research direction in the field of vehicles in recent years[3, 4]. The core of the principle of electromagnetic energy-feeding suspension is the conversion of the form of motion, which can convert the vertical reciprocating vibration of the suspension into the rotary motion or linear motion of other 
mechanisms. The converted motion form is used to drive the generator to complete the power generation recovery and storage or secondary use[5, 6]. In 1996 Suda and Okada "given the concept of regenerative shock absorber using a linear motor but motors were generally costly meanwhile linear motor efficiency was much lower than rotary" [7, 8]. Graves proposed "a rotary DC motor and ball screw mechanism, although the results suggested that some parts still needed to be improved"'[9]. Nakano establish rotating electromagnetic dampers had the gain of mechanical amplification, and that they have developed greater dynamic elements in series to improve the vehicle dynamics[10,11]. Li and Zhang both simulation and test results tested the energyregenerative shock absorber based on rack and pinion mechanism, was proved to be feasible[12, 13]. Liu has stimulated, and modelling of energy regenerative shock absorber develop another system with rotary motor-HESA to obtain higher efficiency and better reliability[14]. Recently Yousaf has been proposed an advanced hydraulic regenerative shock absorber recovered and recovered $4 \%$ suspension energy by using one accumulator[15]. Guo and $\mathrm{Xu}$ also developed the liquid electric energy feeding suspension in which using two accumulators has great efficiency[1620]. They designed the hydraulic electromagnetic regenerative solution and proposed prototype, simulation and dynamic model research. Guntur has studied the hydraulic cylinder and damping force generated electricity bu using regenerative shock absorber[21]. Further, Li also conducted a research on the dynamic characteristics of regenerative shock absorber with a mechanical check valve, to improve the quality of the regenerated power[22]. Wu and long also proposed a HESA prototype analyze the damping force by varying load resistance [23, 24].The main purpose of the research is to optimize the comfort of the vehicle after using the energy-feeding suspension. There is a great energy potential in the car suspension, HESA attract more recognition. Therefore, most of them can be classified into 3 main types currently: Mechanical-hydraulic (including connecting rod type, hydrostatic energy conservation), Electromagnetic (including motor lines, ball screw, gear type, and rack as well electromagnetic coil), and Hydraulic Electromagnetic. US patent Publications "reveal various similar liquid-electric energy-feeding suspensions, which utilize the oil circuit system design to convert the reciprocating vibration energy of the piston into the hydraulic energy of the damping oil, and the hydraulic motor in the driving system rotates"[2528].Observably, many researchers have focused and proposed different concept specific applications but still need to do more research to recovered maximum suspension energy.

The primary goal of the suspension energy recovery system is to meet the basic requirements of the vehicle for damping performance, and then appropriate energy recovery will be performed on this basis. The main research points of this article are aiming at the requirements of the vehicle's vibration-damping performance and performance of the hydraulic energy-feeding shock absorber under no load state is studied. After meeting the basic requirements, the method of changing the load is used to study the energy recovery capacity of the hydraulic energy-supply shock absorber to recover as much energy as possible. This article gives a novel concept and prototype with the combination of hydraulic, electric and mechanical components. It is organized into three sections in which the first section is about the design working principle while parameter settings and mathematical modeling in the second section. Finally in third section simulation tests and experimental results conducted.

\section{Methodology}

\section{Principle analysis of hydraulic energy-feeding shock absorber}

There are two basic principles followed in the design of hydraulic energy-supply shock absorbers. To achieve the vibration damping performance of advanced suspensions and to minimize losses 
and recover part of the energy are following. First to convert the vertical reciprocating motion of the vehicle shock absorber into one way flow of hydraulic energy and use this to drive the hydraulic motor to rotate meanwhile avoiding the energy loss caused by frequent commutation, improving the structural reliability and improving the power generation efficiency of the generator. Secondly, when designing the system structure, it is necessary to consider the asymmetry of the two-stroke damping force of the advanced shock absorber. The damping force curves of the hydraulic energyfeeding shock absorber in the no-load state and the energy-feeding state must meet the requirements. At the same time, the damping force of the system in the no-load state is reduced as much as possible, so that more damping force is provided by the back electromotive force of the generator. Finally after ensuring the damping characteristics of the traditional shock absorber, select the appropriate damping force adjustment method to increase the adjustment range of the damping force as much as possible to prepare for the semi-active control of the subsequent hydraulic energy-feeding shock absorber. The energy harvesting components are hydraulic cylinder in which has compression and expansion section, hydraulic rectifiers, accumulator, electromagnetic generator, and battery as shown in Fig.1.

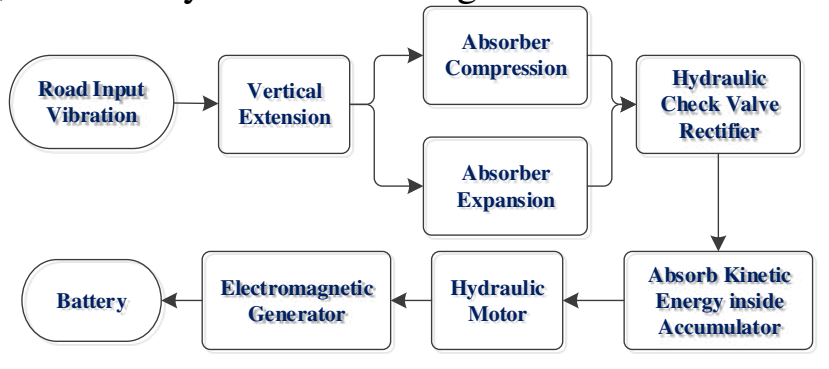

Figure 1. Energy Harvesting Scheme

\section{Working principle of Hydraulic Electromagnetic Regenerative Shock Absorber (HERSA)}

The scheme of the full-bridge hydraulic energy-feeding shock absorber is shown in Fig.2 Where $\mathrm{A}$ is the actuator part and B is the energy feeding part. The actuator part is mainly composed of a hydraulic cylinder, accumulator, and four one-way valves, while the energy feeding part is mainly composed of hydraulic motor, generator and external load. The HERSA model is composed of Hydraulic rectifier, hydraulic motor, hydraulic cylinder, pipelines, generator, accumulator, and so on. The high-pressure oil created by the complementation of shock absorber could be exported to drive hydraulic motor, so as to drive the generator to generate electricity. HRSA is composed of mechanical electrical and hydraulic coupling system. 


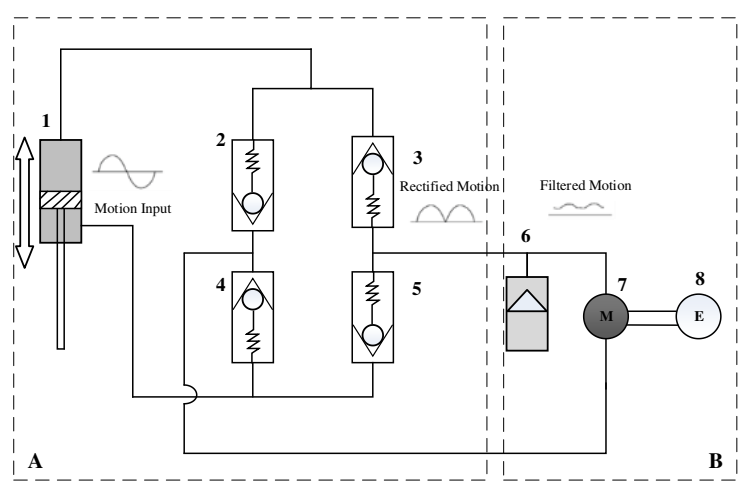

Figure 2. Design working Principle (A) Actuator Part (B)Energy Feeding part(1) hydraulic Cylinder $(2,3,4,5)$ Check Valve (6) Accumulator (7) Hydraulic Motor (8) Generator

The principle of the full-bridge hydraulic energy-feeding shock absorber is to use the idea of the rectifier circuit in the hydraulic oil circuit. The function of the diode in the four one-way valve simulation circuit will be different due to the reciprocating movement of the hydraulic cylinder. The flow direction of the hydraulic oil is rectified into one-way circulating fluid. The rectified oil drives the hydraulic motor on the main road of the oil path to rotate in one direction and then drives the generator to generate electricity through the coupling. The design of the scheme follows the design principle of hydraulic energy feed shock absorber oil one-way flow. Such a design can effectively avoid the loss of rotational inertia caused by frequent reversal of rotating mechanisms such as hydraulic motors and generators, and the life of the overall structural components. When the piston moves upward then fluid moves out from the hydraulic cylinder and enters in check valve 3 because the check valve is 2 closed. This fluid moves towards a high-pressure accumulator after passing it moves into a hydraulic unidirectional motor. The motor rotates clockwise and motor connected further electric generator that produces electricity. The fluid passes through the motor and back in the hydraulic bridge. It enters through check valve 4 and goes back to the hydraulic cylinder because check valve 2 has high pressure. The vibrational motion is converted into unidirectional rectified motion by passing through the hydraulic rectifier. These unidirectional vibrational motion converted into filtered motion after passing through the accumulator. When the hydraulic piston moves down the fluid passes through check valve 5 towards the accumulator and enters into the hydraulic motor. Bypassing through motor the fluid moves through check valve 2 and comes back fluid in the hydraulic cylinder. The high-pressure accumulator always stabilize the fluid pressure and the flow rate of hydraulic fluid in the model and also improve the harvesting energy efficiency. To study the dynamic characteristics of HESA in the shape of anti-pitch performance, a co-simulation model is applied based on AMESim-Matlab/Simulink environment. 


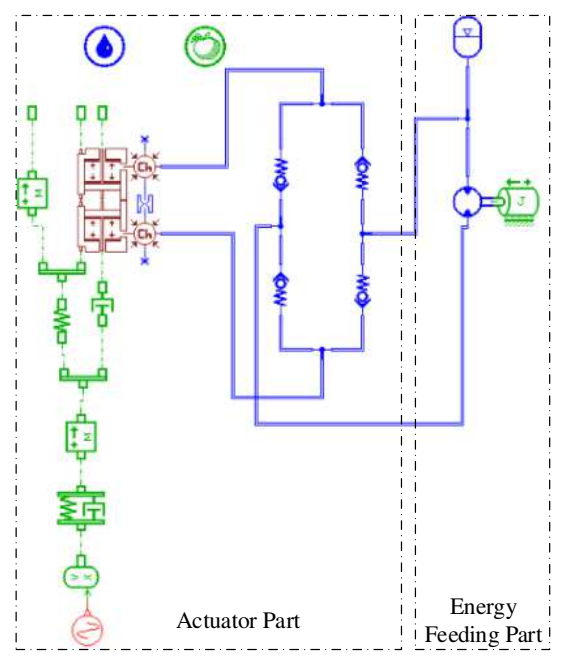

Figure 3. Real Parameters of LMS AMESim Simulation Model

Fig.3 shows the LMS AMESim simulation part in which the hydraulic piston body, car body, tire, accumulator, hydraulic rectifier and hydraulic motor. It can be seen that the oil flow in this model is always in a clockwise direction, thus drives the hydraulic pump to rotate in a one-way direction. In addition, the dynamics of the hydraulic system will be modeled by studying the pressure drops of check valves, a gas reservoir, and a hydraulic pipeline. The LMS regenerative shock absorber energy feeding and electrical parts described as shown in Fig.4.

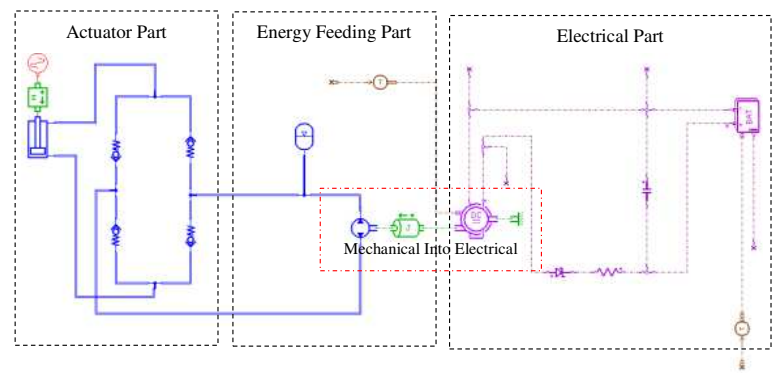

Figure 4. LMS Regenerative Shock absorber Energy Feeding

\section{Mathematical Modeling}

BRP17 is used to refer to the part of a jack or valve that exerts pressure on a body or sleeve of a cylinder or spool. The pressure at the hydraulic shaft port 1 is input in the bar, and the flow rate in $\mathrm{L} / \mathrm{min}$ and a volume in $\mathrm{cm}_{3}$ is computed and output at this port.

The current chamber length

$$
\operatorname{vol}_{1}=\text { length } \times \frac{\pi}{4}\left(d_{p}^{2}-d_{r}^{2}\right)
$$

The flow rate at port 1 of the piston moving body is 


$$
q_{1}=\left(v_{3}-v_{2}\right) \times \frac{\pi}{4}\left(d_{p}^{2}-d_{r}^{2}\right) \frac{\rho\left(p_{1}\right)}{\rho(0)}
$$

Force at port 3 of the piston moving body

$$
f_{3}=f_{4}+p_{1} \times \frac{\pi}{4}\left(d_{p}^{2}-d_{r}^{2}\right)
$$

The volume of the chamber formed by the body and the piston is computed from the displacements received on ports 2 and 3 of the piston moving body. Port 1 is normally connected to a pressure source, a conventional hydraulic line submodel, or an HCD hydraulic chamber submodel in which $\mathrm{dp}$ and $\mathrm{dr}$ are piston and rod diameter respectively.

The accumulator gas is assumed to be an ideal gas obeying the normal gas law:

$$
p . v=m \cdot R \cdot T
$$

The irregular motion of non-ideal gas is more complicated, so when studying the mathematical model of the airbag-type accumulator, the gas in the airbag-type accumulator is assumed to be the ideal gas. Ideal gas meets.

$$
P_{1} V_{1}^{n}=P_{2} V_{2}^{n}=\text { Constant }
$$

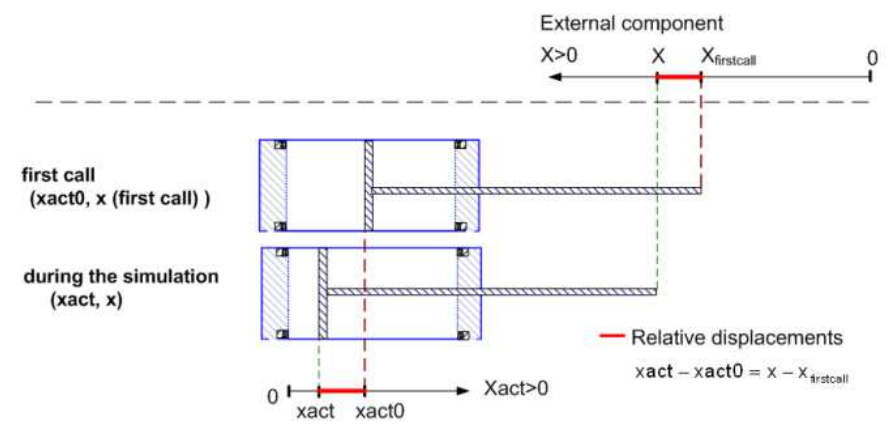

Figure 5. Double Hydraulic Chamber Single Rod jack Stroke

The double hydraulic chamber is a single rod jack, actuator or cylinder with a fixed body as shown in Fig.5. The submodel includes pressure dynamics in the volumes either side of the piston, viscous friction, and leakage past the piston.

The force exerted by the rod due to the pressures and viscous friction is:

$$
f_{\text {rod }}=p_{1} A_{1}-p_{2} A_{2}+v \cdot \text { vics }
$$

Where $A_{1}$ is the cross-sectional area of the piston on which pressure $\mathrm{p}_{1}$ acts and $\mathrm{A}_{2}$ the annular area on which pressure $\mathrm{p}_{2}$ acts.

The force of the hydraulic piston body 


$$
F=P \frac{\pi\left(D^{2}-r^{2}\right)}{4}
$$

Where $\mathrm{D}$ is the piston diameter and $\mathrm{r}$ is rod diameter

The inflow in the chamber at port 1 is

$$
\text { inflow }_{1}=q_{1}-q_{\text {leak }}-v \cdot A_{1} \cdot \frac{\rho\left(p_{1}\right)}{\rho(0)}
$$

Thus, the derivative of the pressure at port 1 "p1dot" is computed with the utility hydraulic capacitive element from a pressure "p1", a volume "vol1" and the inflow "inflow1".Similarly at port 2 flow rate in the chamber

$$
\text { inflow }_{2}=q_{2}-q_{\text {leak }}-v \cdot A_{2} \cdot \frac{\rho\left(p_{2}\right)}{\rho(0)}
$$

The air chamber is simplified as a spring damping system

$$
\left(p_{b}-p_{a}\right) A_{a}=k_{e} \frac{V_{a}}{A_{a}}+c_{e} \frac{1}{A_{a}} \frac{d V_{a}}{d t}
$$

Gas damping coefficient is

$$
c_{e}=8 \pi \mu l=8 \pi \mu \frac{V_{a}}{A_{a}}
$$

$\mu$ is Accumulator gas viscosity coefficient

The calculation formula of gas stiffness coefficient is

$$
k_{e}=\frac{\Delta F}{\Delta x}=\frac{\Delta p \times A}{\Delta V / A}=A_{a}^{2} \frac{d p}{d V}=A_{a}^{2} \frac{n p_{a 0}}{V_{a 0}}
$$

Where $\mathrm{Aa}$ cross-section area of accumulator $\mathrm{Va}$ volume of the gas $\mathrm{Pa}$ gas pressure in the accumulator. The gas in the gas chamber of the bladder-type accumulator is easy to compress due to the small gas stiffness.

Suppose tire is subjected to force excitation, the vibration energy governing equations is:

$$
m_{a} a_{2}+c_{e q}\left(v_{2}-v_{1}\right)+K_{2}\left(x_{2}-x_{1}\right)=0
$$

And

$$
m_{1} a_{1}+c_{e q}\left(v_{1}-v_{2}\right)+K_{2}\left(x_{1}-x_{2}\right)+K_{1} x_{1}=F \sin (\omega t)
$$


In equ.Error! Reference source not found. some parameters in which $\mathrm{x} 1$ and $\mathrm{x} 2$ are the car body and tire displacement, $\mathrm{m}_{1}$ and $\mathrm{m}_{2}$ are the wheel masses, $\mathrm{k}_{1}$ and $\mathrm{k}_{2}$ are the tires and suspension stiffness respectively, a1, and a2 are the corresponding acceleration of the body, tire respectively, $\mathrm{v} 1$ and $\mathrm{v} 2$ are the corresponding speed of body and tire respectively, $\mathrm{t}$ is the time, $\omega$ is the frequency, ceq is the HESA equivalent damping coefficient and $\mathrm{F}$ is the maximum force.

$$
x_{2}-x_{1}=\left(X_{2}-X_{1}\right) \sin (\omega t-\theta)
$$

Total damping is

$$
c_{e q}=c_{c}+c_{e}
$$

Equivalent damping coefficient is

$$
c_{e}=\left(\frac{2 \pi A}{q}\right)^{2} \frac{\eta_{v}}{\eta_{m}} \frac{K_{v} K_{t}}{R_{\text {in }}+R_{\text {load }}}
$$

In addition, the regenerative power Pre can be obtained by an electric current I and the electric load resistance $\mathrm{Rex}_{\mathrm{e}}$

$$
P_{r e}=I^{2} R_{e x}
$$

Table 1. Quarter car Parameters

\begin{tabular}{ccc}
\hline Symbol & Valve & Units \\
\hline $\boldsymbol{m}_{\boldsymbol{1}}$ & 40 & $\mathrm{~kg}$ \\
$\boldsymbol{m}_{\boldsymbol{2}}$ & 350 & $\mathrm{~kg}$ \\
$\boldsymbol{k}_{\boldsymbol{1}}$ & 200 & $\mathrm{KN} / \mathrm{m}$ \\
$\boldsymbol{k}_{\boldsymbol{2}}$ & 20 & $\mathrm{KN} / \mathrm{m}$ \\
$\boldsymbol{F}$ & 1000 & $\mathrm{~N}$ \\
$\boldsymbol{c} \mathbf{c}$ & 520 & $\mathrm{~N} / \mathrm{m} / \mathrm{s}$ \\
$\boldsymbol{k}_{\mathbf{v}}$ & 0.07 & $\mathrm{volts} / \mathrm{rad} / \mathrm{s}$ \\
$\boldsymbol{k}_{\boldsymbol{t}}$ & 0.06 & $\mathrm{~N} / \mathrm{amp} / \mathrm{m}$ \\
$\boldsymbol{R}_{\boldsymbol{n}}$ & 1 & $\mathrm{ohm}$ \\
$\boldsymbol{q}$ & 5 & $\mathrm{cc} / \mathrm{cycle}$ \\
$\boldsymbol{A}$ & 1963.5 & $\mathrm{~mm} 2$ \\
$\boldsymbol{\eta}_{\boldsymbol{v}}$ & 0.88 & \\
$\boldsymbol{\eta}_{\boldsymbol{m}}$ & 0.9 & \\
\hline
\end{tabular}

The temperature of the gas is modeled using an energy balance with heat exchange with the environment. The heat exchange with the environment is modeled with a time constant. If this is large, i.e. no heat exchange, the accumulator becomes an adiabatic process. If small, it approaches the behavior of an isothermal process. When it is fully discharged, the hydraulic pressure is computed using the equation for a compressible volume of fluid with an assumed volume of 1/1000 of the accumulator volume.

\section{Workbench}

In order to evaluate the effect of different excitation rates and external loads on the feed energy damper, a test setup was installed. The existing hydraulic excitation platform was used to model 
road excitation. As shown in Fig.6 the test bench mainly consists of double-acting hydraulic cylinders, check valves, accumulators, hydraulic motors, generators, powerful sliding rheostats and compression sensors, and tensile loads.

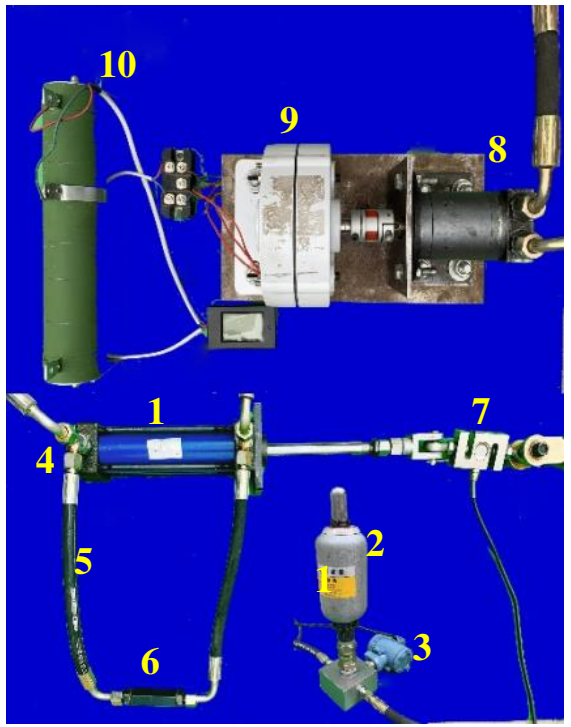

Figure 6. Prototype of Hydraulic Regenerative shock Absorber (1) Hydraulic cylinder (2) Accumulator (3) Pressure Transducer $(4,6)$ Hydraulic Rectifier (5) Hose (7) Force Transducer (8) Hydraulic Motor (9) Three Phase alternator (10) Sliding Rheostat

The hydraulic excitation platform adjusts to change the excitation speed, and sliding rheostat. The external load of the compressive load and tensile load orthogonal test value get from the sensor and use the data acquisition tool to collect the voltage value on the sliding rheostat as shown in Fig.7.

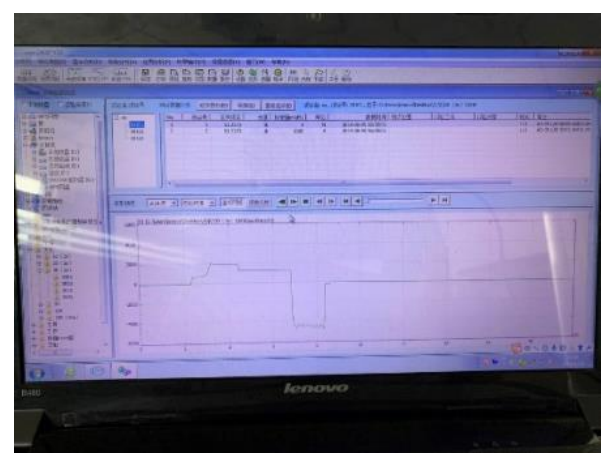

Figure 7. Data Acquisition

Table 2. Parameters of Hydraulic Regenerative Shock Absorber

\begin{tabular}{ccc}
\hline Parameters & Unit & Value \\
\hline Car Body Mass & $\mathrm{Kg}$ & 600 \\
Tyre mass & $\mathrm{Kg}$ & 50 \\
Accumulator Pressure & $\mathrm{bar}$ & 10,15 \\
\hline
\end{tabular}




\begin{tabular}{ccc}
\hline Accumulator Volume & $\mathrm{L}$ & $1.2,1.4,1.6$ \\
Motor displacement & $\mathrm{cc} / \mathrm{rev}$ & $8,12,16$ \\
Road signal & $\mathrm{Hz}$ & $0.33,1,1.67$ \\
Check Valve Pressure & $\mathrm{bar}$ & 10 \\
\hline
\end{tabular}

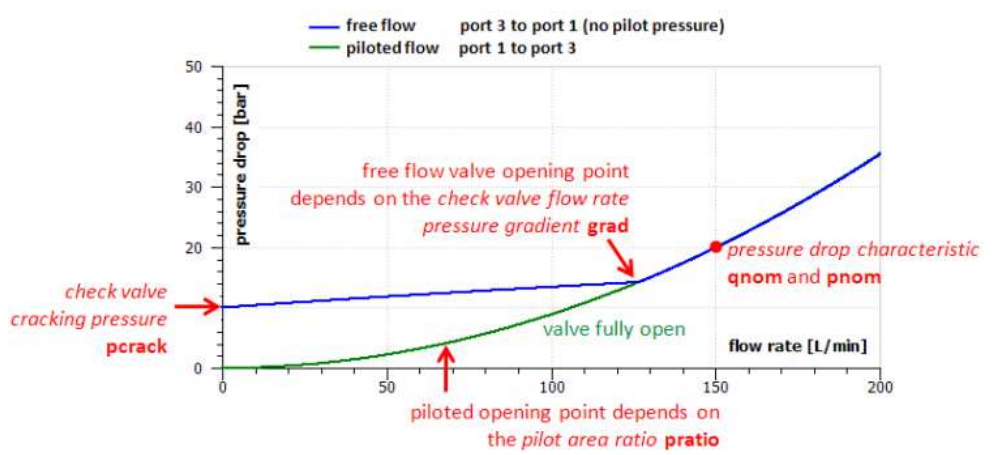

Figure 8. Hydraulic Check Valve Pressure Flow rate Curves

The Slope of the flow-pressure curve in the range where the valve is not fully opened. For this model, the computed flow-pressure characteristic is not linear as shown in Fig.8. The hydraulic check valve has a control piston in addition to the basic check valve. Additional pressure gap needed to actually open or close the valve (due to internal friction). It is expressed as a pressure. This parameter is compared to a pressure difference and will not be converted when units are changed from absolute to relative pressures.

A pressure drop $p 3$ - $p 1$ cycle is imposed through the valve. The pressure drop starts from 10 bar, rises up to $17 \mathrm{bar}$ and falls down again to $10 \mathrm{bar}$. No pilot pressure is applied to the valve. The hysteresis is set to 8 bar as shown in Fig.9.
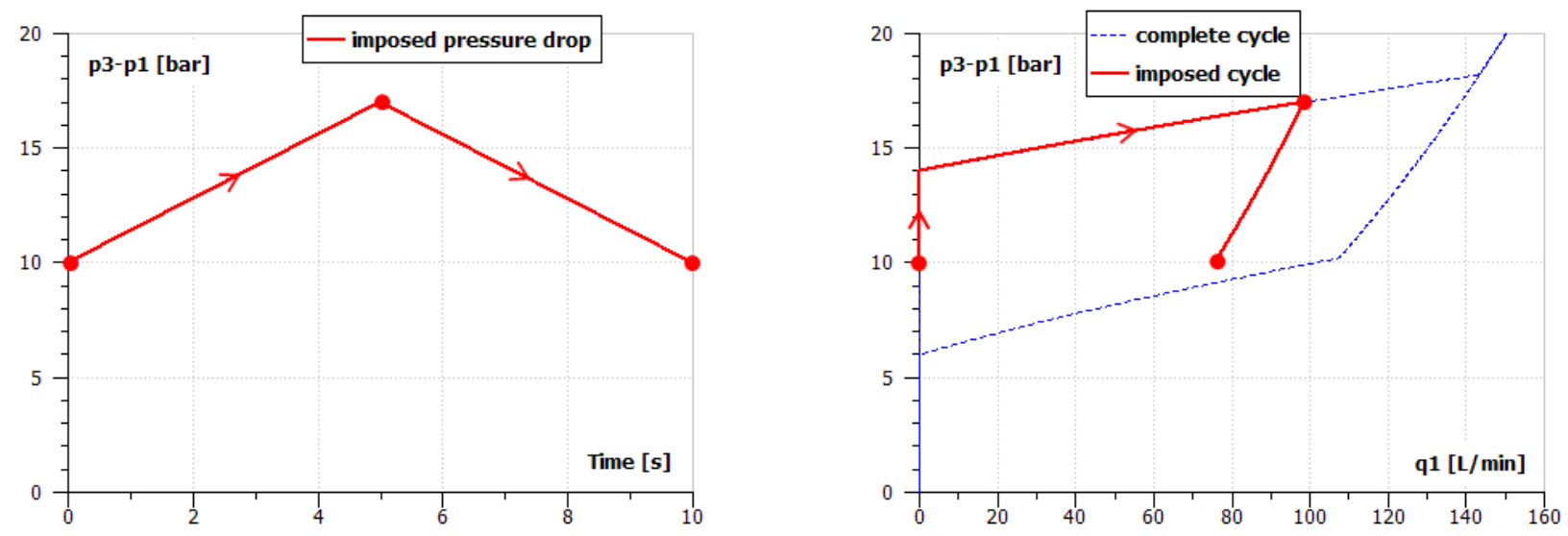

Figure 9. Hysteresis behavior of Hydraulic Rectifier

First, the pressure drop increases from 10 bar to 14 bar. While in this pressure range, the fractional valve opening remains null because of the hysteresis. The hysteresis cycle implies that the output volumetric flow rate follows the "increase dp curve" until p3 - p1 reaches the pressure peak 17 bar. Then, the pressure drop decreases but the fractional valve opening remains constant 
because of the hysteresis and the volumetric flow rate follows an orifice law with a constant crosssectional area until p3 - p1 reaches 10 bar.

Table 3. Real Parameters of Hydraulic Rectifier

\begin{tabular}{cccc}
\hline Parameters & Symbol & Unit & Value \\
\hline Check valve cracking pressure & pcrack & bar & 10 \\
Check valve flow rate pressure gradient & grad & $\mathrm{L} / \mathrm{min} / \mathrm{bar}$ & 30 \\
Characteristic flow rate at maximum opening & qnom & $\mathrm{L} / \mathrm{min}$ & 100 \\
Valve damping ratio & zeta & $\mathrm{null}$ & 1.8 \\
Valve natural frequency & wn & $\mathrm{Hz}$ & 1.6 \\
Valve hysteresis & hyst & bar & 4 \\
\hline
\end{tabular}

\section{Results and Discussion}

\section{Compression/Extension damping force ratios from different piston diameter}

The characteristics of hydraulic regenerative shock absorber is investigated and analyzed considering different sinusoidal excitation frequency, load and conditions. Due to the inherent feature of the hydraulic actuator, different ratios of jerk/rebound damping forces that balance the tire-road contact and body vibration acceleration can be achieved by adjusting the flow rate ratio in the Jerk / Rebound process. The working cylinder diameter of the hydraulic piston is adjusted $50 \mathrm{~mm}$ and its shows that the maximum damping force during extension stroke while in adjusting the piston diameter respectively $20 \mathrm{~mm}, 30 \mathrm{~mm}, 40 \mathrm{~mm}$ in which the damping force during compression stroke is greater that gives less damping forces and less efficient as shown in the Fig. 10. Based on Equ. 6 the damping force F is determined by drod and dp respectively diameters of rod and piston. The velocity is same at different piston diameters. The shaft speed is a key parameter of the hydraulic motor to shows different behavior at different piston diameters as shown in Fig. 11. By changing the rod diameter at different $\mathrm{mm}$ the velocity and displacement of the moving body doesn't change. According to the requirements of the target Sport utility vehicle, the piston diameter is set to $50 \mathrm{~mm}$ in this article.



Figure 10. Piston Body Force at different piston diameter 


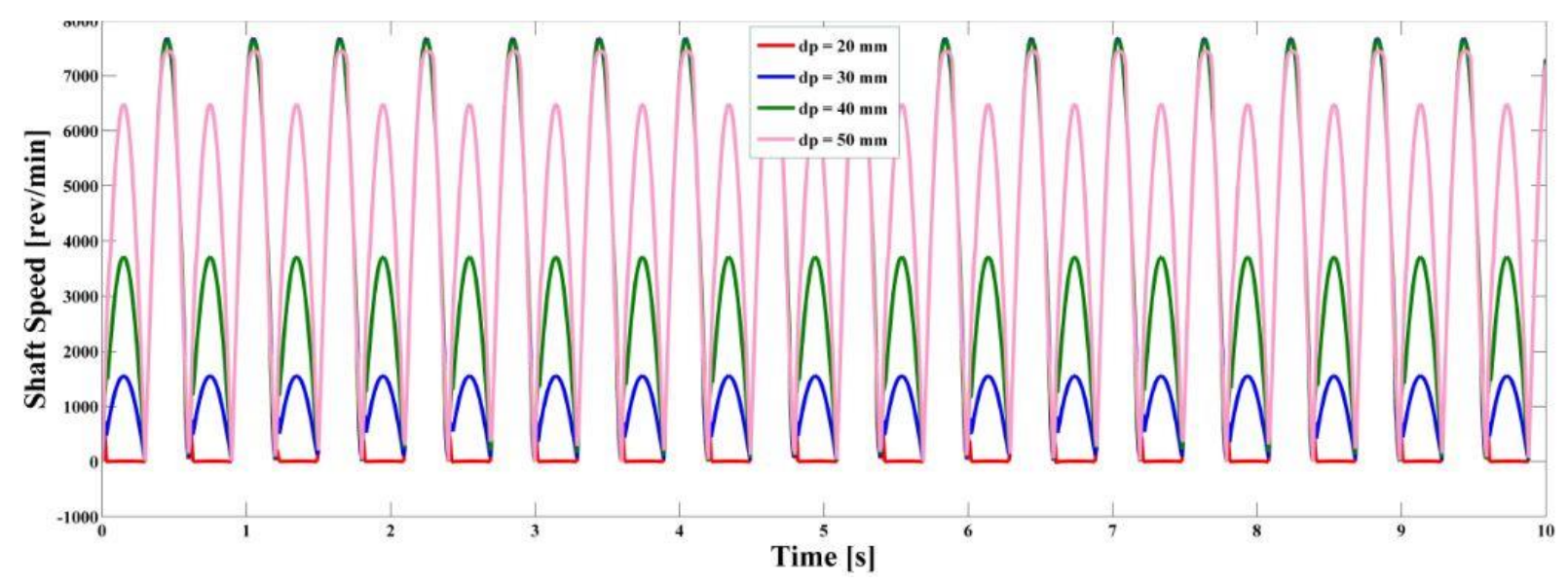

Figure 11. Shaft Speed at different Piston Diameter

Damping power of piston velocity of $0.52 \mathrm{~m} / \mathrm{s}$ of the time resistance. The model has compression energy $\mathrm{F}_{1}, 3367.65 \mathrm{~N}$, and expansion force $\mathrm{F}_{2}, 3676.107 \mathrm{~N}$, and recovery resistance $7043 \mathrm{~N}$ as shown in Fig. 12.

$$
\text { Rate }=\frac{F_{2}}{F_{1}}=\frac{3676.10}{3367.65}=1.09
$$

The positive side of the absorber is in the compression stroke and the extension stroke is negative. The actual factors of the sine wave frequency are $1.67 \mathrm{~Hz}$, and the phase shift is 270-degree as shown in Fig. 12.

Table 4. Damping Force at Different Cylinder Diameter

\begin{tabular}{ccc}
\hline Cylinder Diameter mm & Recovery Resistance N & Compression Resistance N \\
\hline 20 & $200-1200$ & $100-600$ \\
30 & $1000-2800$ & $200-900$ \\
40 & $1500-4500$ & $400-1800$ \\
50 & $4000-7000$ & $700-2800$ \\
\hline & &
\end{tabular}

Figure 12. Force Energy Ratio Curves 
According to QC/T 545-1999 national Standard, the test parameter of the piston velocity is 0.52 $\mathrm{m} / \mathrm{s}$ required and results show the exact value of the velocity of advanced hydraulic regenerative shock absorber calculated and full the standard requirement for dissipation of suspension as shown in Fig.13.

$$
V=\frac{\pi \times s \times n}{6} \times 10^{-4}=0.52 \mathrm{~m} / \mathrm{s}
$$

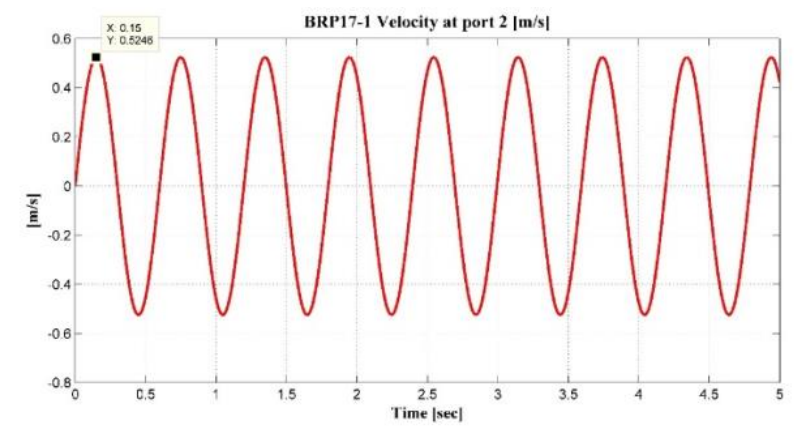

Figure 13. Velocity of advanced hydraulic regenerative shock absorber

The simplified stimulation to a car model velocity, road profile and force shown in Fig.14(a). Based on Equ. 8 the average peak value of the piston force $1552 \mathrm{~N}$ and average velocity is $0.52 \mathrm{~m} / \mathrm{s}$. Fig.14(b) shows that when the external load was $49 \Omega$, the maximum extension and compression damping force reached $-6972 \mathrm{~N}$ and $2768 \mathrm{~N}$, respectively, which basically meets the target damping requirement. The peak power can be recovered at $497.52 \mathrm{~W}$, and the feed efficiency is $13.5 \%$.

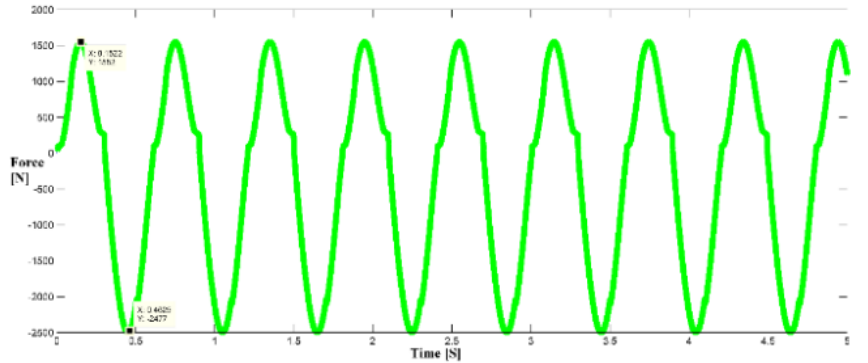

(a)

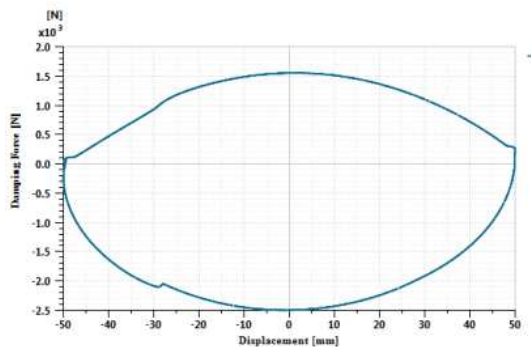

(b)

Figure 14. (a)Damping Piston Force; (b) Damping Characteristics Curves

The experimental and simulated hydraulic rectified shows the motion rectified and changed into unidirectional motion meanwhile decreases the amplitude of motion curves after passing the hydraulic check valve that reflect the ride comfort by longitudinal dynamic responses as shown in Fig.15(a).The output simulation of the Matlab/Simulink is the relative velocity of the sprung and unsprung mass which can be used as the input of HIS-HESA in AMESim platform. Furthermore, the output of the AMESim is a damping force that is used as the input of the vehicle part in Matlab/Simulink. A warp excitation is established to investigate the characteristics of damping force at different sinusoidal excitation frequencies as shown in Fig.15(b). 


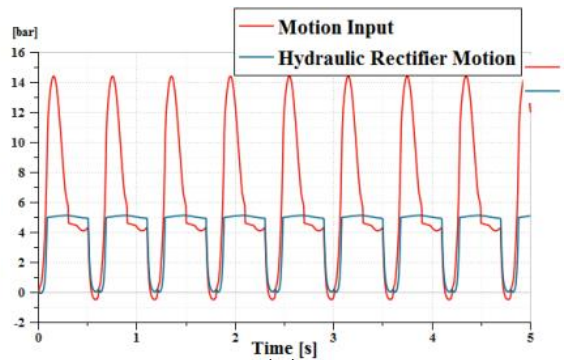

(a)

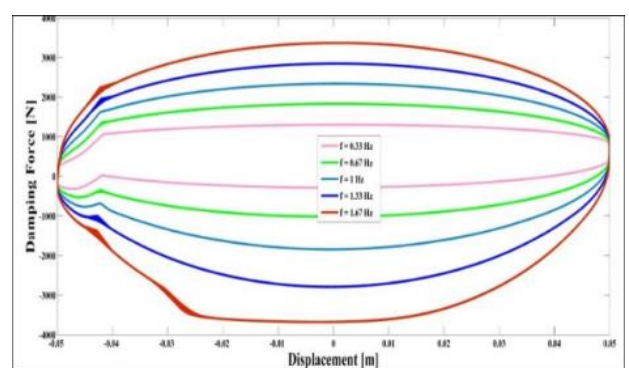

(b)

Figure 15. (a) Hydraulic Rectified Motion Curves; (b) Damping Characteristics Curves at different frequency

Hydraulic motor is no flow losses or mechanical losses and the flow rate is determined solely by the shaft speed and the displacement and the inlet port pressure. When the motor is rotated backward, the port that is nominally the outlet (port 1) becomes the inlet. Under these conditions, the pressure at port 1 is used in determining the flow rate as shown in Fig.16(a). To avoid a discontinuity, a smooth switch between the pressures is used. The maximum shaft speed get at $1.67 \mathrm{~Hz} 33.18 \mathrm{Krev} / \mathrm{min}$. The velocity displacement curves at different frequency curves shown in Fig.16(b).

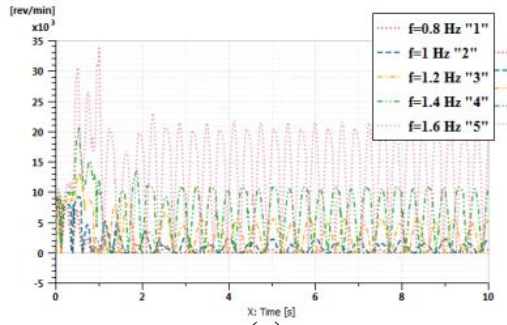

(a)

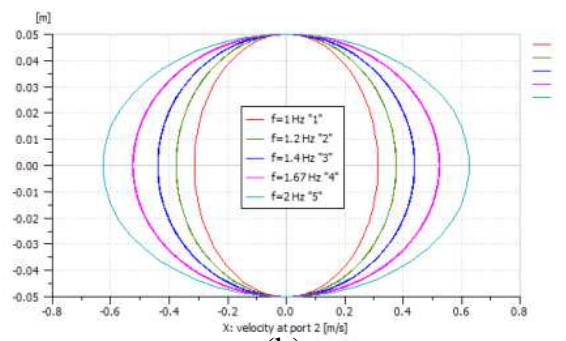

(b)

Figure 16. (a) Shaft Speed; (b)Velocity Displacement Curves at Different frequency Curves at different frequency

When piston diameter $50 \mathrm{~mm}$ and rod diameter $20 \mathrm{~mm}$ set in the model to construct hydraulic jacks and spool valves with moving bodies. The displacement of the moving piston body is $0.0154 \mathrm{~m}$ and velocity $0.49 \mathrm{~m} / \mathrm{s}$ that shows our model absorbed maximum damping force and it gives ride comfort for vehicle basically meets the target damping requirement as shown in Fig.17.

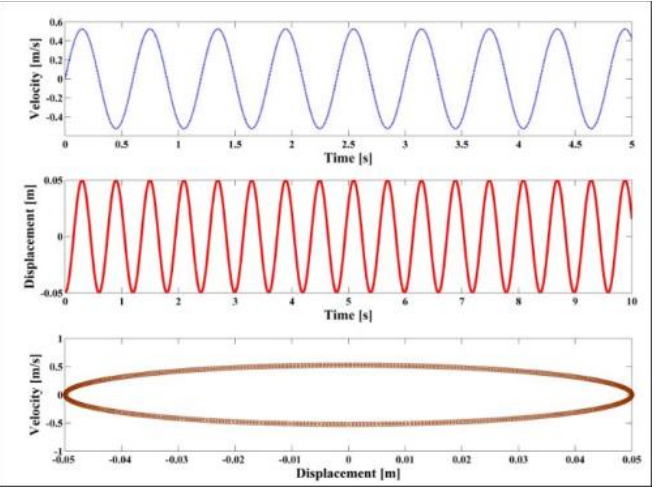

Figure 17. Velocity and Displacement of the moving piston body Curves 
The simulation results show, increasing input velocity will increase the energy absorbing capacity of the shock absorber, indicated by the area covered by the force-displacement curve as shown in Fig.18.

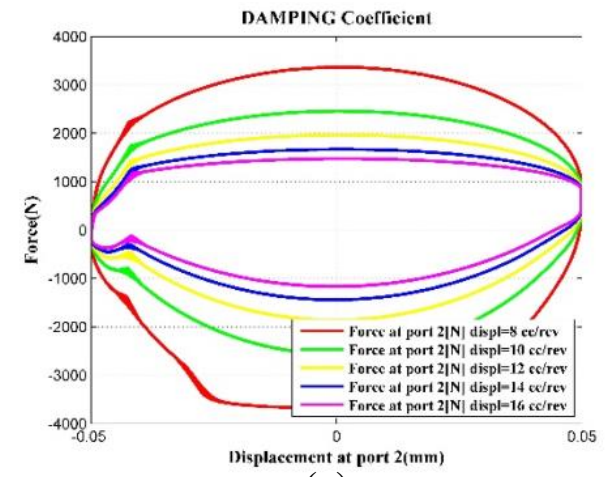

(a)

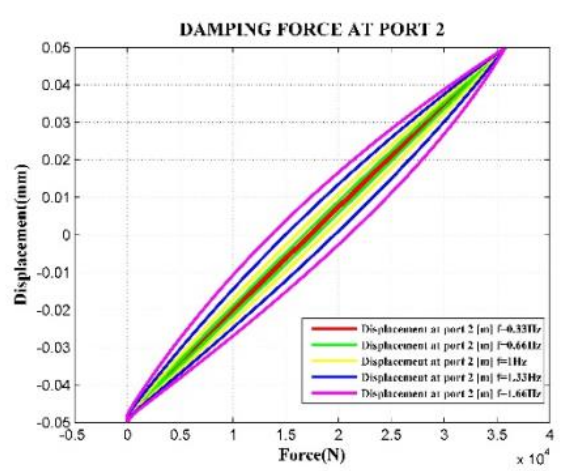

(b)

Figure 18. (a) Damping force at different displacement; (b) Damping force at different Sinosidal Frequency

\section{Conclusion}

This work shows the prototype of hydraulic regenerative shock absorber and energy recovery analysis, active control of HESA are carried out based on a quarter car model combined with LMS simulation results on different excitation frequency and piston amplitude. The damping characteristic and energy-regenerative characteristics of the HESA are investigated, and the energy recovery of the HESA is analyzed. The energy recover power first increases and then decreases as the load resistance increases gradually at any excitation frequency as results described, and the optimal load resistance is changeable as the excitation frequency changes. The damping force of extension stroke is always greater than the compression stroke. Estimating the energy-harvesting potentiality out of the damping events based on different vehicles, different road modes, and different driving circumstances, including the standard driving cycles. Conducting on-field experimentations regarding the quantification of the energy-harvesting content during the damping process, including both the off-road vehicles and on-road vehicles concerning different driving speeds and road sections. By the experimentally and simulation model results recovered wasted energy into useable electrical energy at different excitation frequencies and provide maximum ride comfort. The external load was $49 \Omega, 1.67 \mathrm{~Hz}$ frequency, piston diameter $50 \mathrm{~mm}$ then maximum extension and compression damping force reached $-6972 \mathrm{~N}$ and $2768 \mathrm{~N}$, respectively, which basically meets the target damping requirement. At the sametime, the peak power can be recovered at $497.52 \mathrm{~W}$, and the feed efficiency is $13.5 \%$. The feasibility of damping forces of HESA is inveterate by the experiments, though there still need much further study.

\section{Future work}

In the test bench and simulation the value of damping characteristics curves and speed curves discussed at different frequencies while in the future can do research taking different motor displacement $\mathrm{cc} / \mathrm{r}$ and typical speed of the motor $8000 \mathrm{r} / \mathrm{min}$. In the benchmark test, the value of the external resistor is theoretically selected to be $1.66 \Omega$, so as to obtain the required damping coefficient according to the linear damping coefficient. The regenerative shock absorbers with 
different external resistor values will be tested in the MTS experiment to study the actual mechanical feedback and performance.

\section{Availability of data and material}

All data generated or analysed during this study are included in this published article.

\section{Authors' Contributions}

Muhammad Yousaf Iqbal was in charge of the whole trial, and wrote the manuscript, sampling and laboratory analyses. All authors read and approved the final manuscript.

\section{Competing Interests}

The authors declare that they have no competing interests.

\section{Funding}

Supported by Shanxi Provincial Department of Education, 2018-2019 (Grant No. 20181102006).

\section{Affiliations}

Taiyuan University of Technology Shanxi China

\section{Acknowledgements}

The authors sincerely thanks to Dr. Zhifei Wu of Taiyuan University of Technology for his critical discussion and reading during manuscript preparation.

\section{References}

[1] A.S. Rattner, S. Garimella, Energy harvesting, reuse and upgrade to reduce primary energy usage in the USA, Energy 36(10) (2011) 6172-6183.

[2] L. Zuo, B. Scully, J. Shestani, Y. Zhou, Design and characterization of an electromagnetic energy harvester for vehicle suspensions, Smart Materials and Structures 19(4) (2010) 045003.

[3] K. Guo, Y. Zhang, X. Zhang, H. Cui, F. Ma, Thermo-mechanically coupled of shock absorber-current state of research and future directions, J. Mach. Des. Res. 30(3) (2014) 1-6.

[4] Z. Li, L. Zuo, G. Luhrs, L. Lin, Y.-x. Qin, Electromagnetic energy-harvesting shock absorbers: design, modeling, and road tests, IEEE Transactions on vehicular technology 62(3) (2012) 1065-1074.

[5] Z. Jin-qiu, P. Zhi-zhao, Z. Lei, Z. Yu, A review on energy-regenerative suspension systems for vehicles, Proceedings of the world congress on engineering, 2013, pp. 3-5.

[6] S. Liu, H. Wei, W. Wang, Investigation on some key issues of regenerative damper with rotary motor for automobile suspension, Proceedings of 2011 International Conference on Electronic \& Mechanical Engineering and Information Technology, IEEE, 2011, pp. 1435-1439.

[7] Y. Suda, T. Shiiba, A new hybrid suspension system with active control and energy regeneration, Vehicle System Dynamics 25(S1) (1996) 641-654.

[8] Y. Okada, H. Harada, Regenerative control of active vibration damper and suspension systems, Proceedings of 35th IEEE conference on decision and control, IEEE, 1996, pp. 4715-4720.

[9] K.E. Graves, P.G. Iovenitti, D. Toncich, Electromagnetic regenerative damping in vehicle suspension systems, International Journal of Vehicle Design 24(2-3) (2000) 182-197.

[10] K. Nakano, Y. Suda, S. Nakadai, Self-powered active vibration control using a single electric actuator, Journal of Sound and Vibration 260(2) (2003) 213-235.

[11] K. Nakano, Combined type self-powered active vibration control of truck cabins, Vehicle System Dynamics 41(6) (2004) 449-473. 
[12] Z. Li, Z. Brindak, L. Zuo, Modeling of an electromagnetic vibration energy harvester with motion magnification, ASME 2011 International Mechanical Engineering Congress and Exposition, American Society of Mechanical Engineers Digital Collection, 2011, pp. 285-293.

[13] R. Zhang, X. Wang, Parameter study and optimization of a half-vehicle suspension system model integrated with an arm-teeth regenerative shock absorber using Taguchi method, Mechanical Systems and Signal Processing 126 (2019) 65-81.

[14] J. Liu, X. Li, X. Zhang, X. Chen, Modeling and simulation of energy-regenerative active suspension based on BP neural network PID control, Shock and Vibration 2019 (2019).

[15] M.Y. Iqbal, Z. Wu, G. Xu, S.A. Bukhari, Study of External Characteristics of Hydraulic Electromagnetic Regenerative Shock Absorber, World Journal of Engineering and Technology 7(3) (2019) 520-535.

[16] L. Xu, Structure designs and evaluation of performance simulation of hydraulic transmission electromagnetic energy-regenerative active suspension, SAE Technical Paper, 2011.

[17] Z. Fang, X. Guo, L. Xu, H. Zhang, Experimental study of damping and energy regeneration characteristics of a hydraulic electromagnetic shock absorber, Advances in Mechanical Engineering 5 (2013) 943528.

[18] H. Zhang, X. Guo, L. Xu, S. Hu, Z. Fang, Parameters analysis of hydraulic-electrical energy regenerative absorber on suspension performance, Advances in Mechanical Engineering 6 (2014) 836502.

[19] H. Zhang, X. Guo, L. Xu, J. Zhang, Simulation and test for hydraulic electromagnetic energy-regenerative shock absorber, Transactions of the Chinese Society of Agricultural Engineering 30(2) (2014) 38-46.

[20] Z. Fang, X. Guo, L. Xu, H. Zhang, An optimal algorithm for energy recovery of hydraulic electromagnetic energy-regenerative shock absorber, Applied Mathematics \& Information Sciences 7(6) (2013) 2207.

[21] H.L. Guntur, Analysis of the influence of hydraulic cylinder diameter to the total damping force and the generated electricity of regenerative shock absorber, ARPN Journal of Engineering and Applied Sciences 11(2) (2016) 873-878. [22] Z. Li, L. Zuo, J. Kuang, G. Luhrs, Energy-harvesting shock absorber with a mechanical motion rectifier, Smart materials and structures 22(2) (2012) 025008.

[23] Z. Wu, G. Xu, Modeling and Analysis of a Hydraulic Energy-Harvesting Shock Absorber, Mathematical Problems in Engineering 2020 (2020).

[24] G. Long, F. Ding, N. Zhang, J. Zhang, A. Qin, Regenerative active suspension system with residual energy for in-wheel motor driven electric vehicle, Applied Energy 260 (2020) 114180.

[25] D.L. Margolis, M.R. Jolly, W.R. Schroeder, M.C. Heath, D.E. Ivers, Regenerative system including an energy transformer which requires no external power source to drive same, Google Patents, 1996.

[26] J.A. Stansbury III, Regenerative suspension with accumulator systems and methods, Google Patents, 2012.

[27] A. Okamoto, Energy regeneration device for either hybrid vehicle or electric automobile, Google Patents, 2013.

[28] S. Carabelli, A. Tonoli, A. Festini, F. Cavalli, N. Amati, Suspension system for a wheeled vehicle and a wheeled vehicle equipped with such a suspension system, Google Patents, 2011. 
Figures

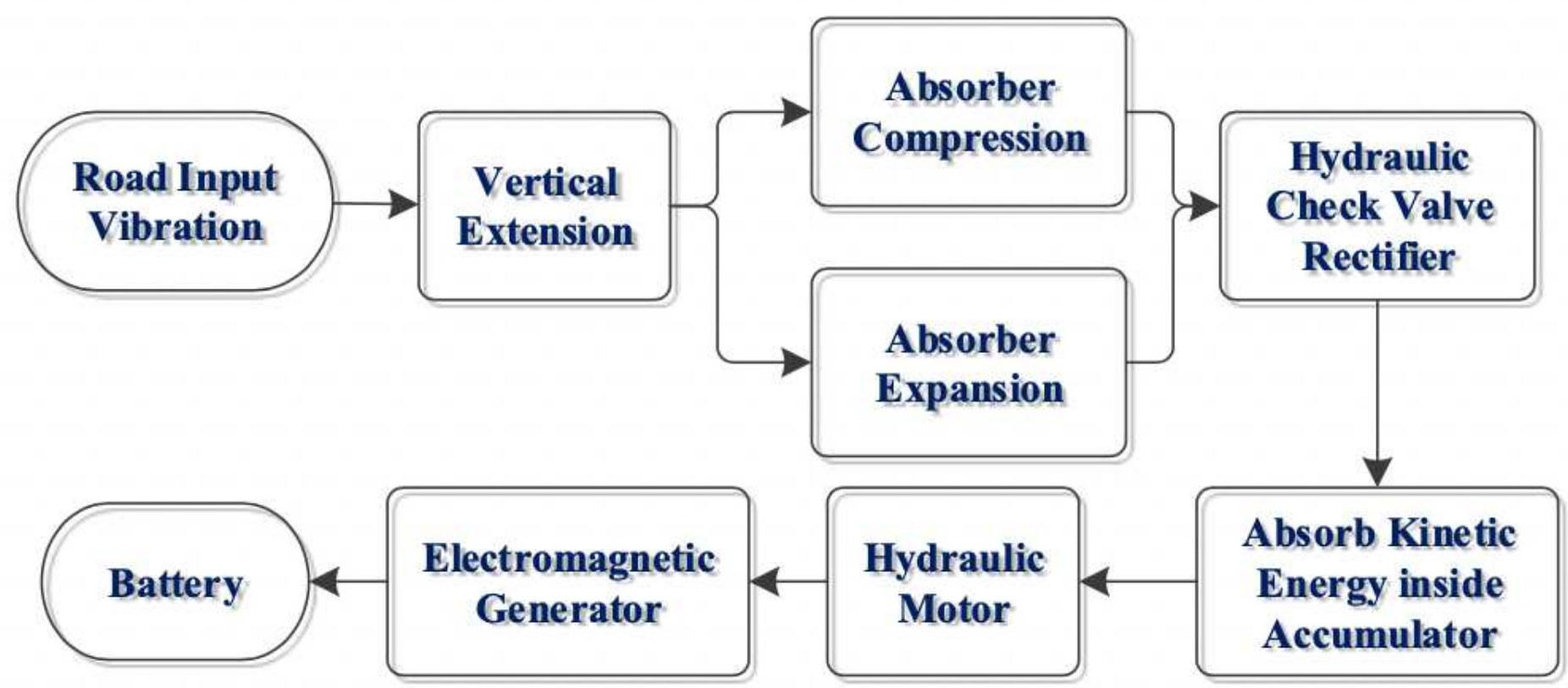

Figure 1

Energy Harvesting Scheme 


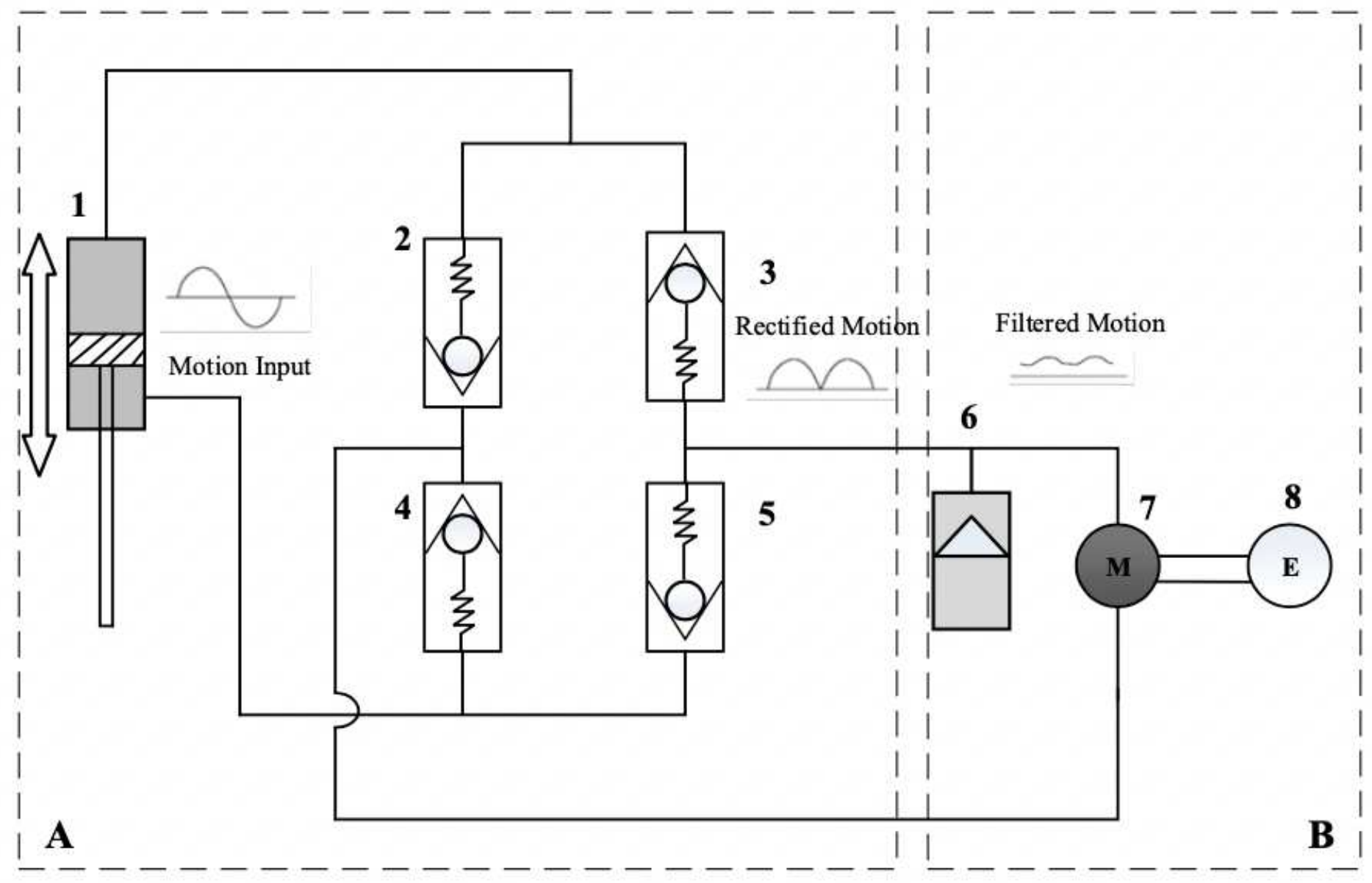

Figure 2

Design working Principle (A) Actuator Part (B)Energy Feeding part(1) hydraulic Cylinder $(2,3,4,5)$ Check Valve (6) Accumulator (7) Hydraulic Motor (8) Generator 


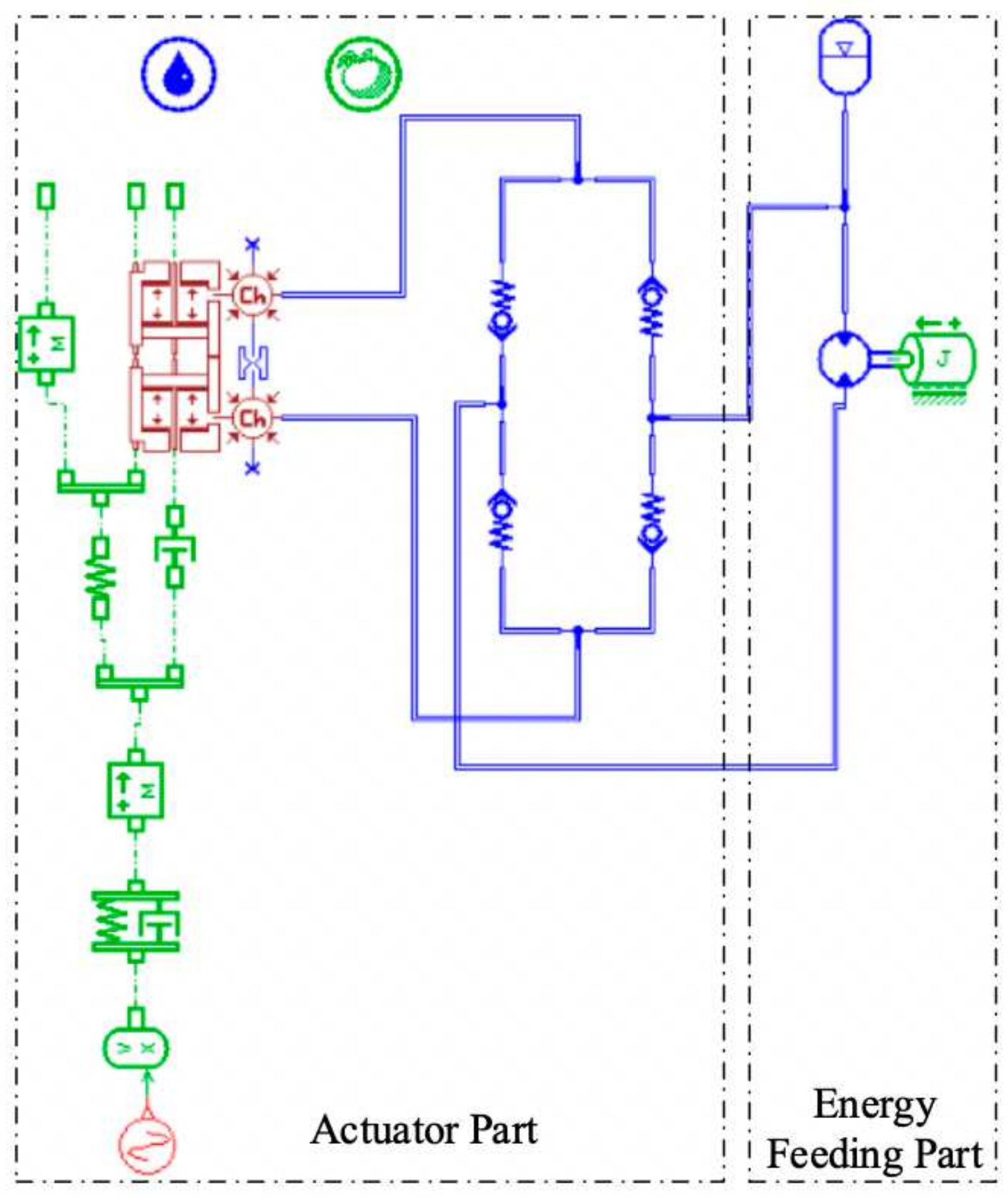

Figure 3

Real Parameters of LMS AMESim Simulation Model 


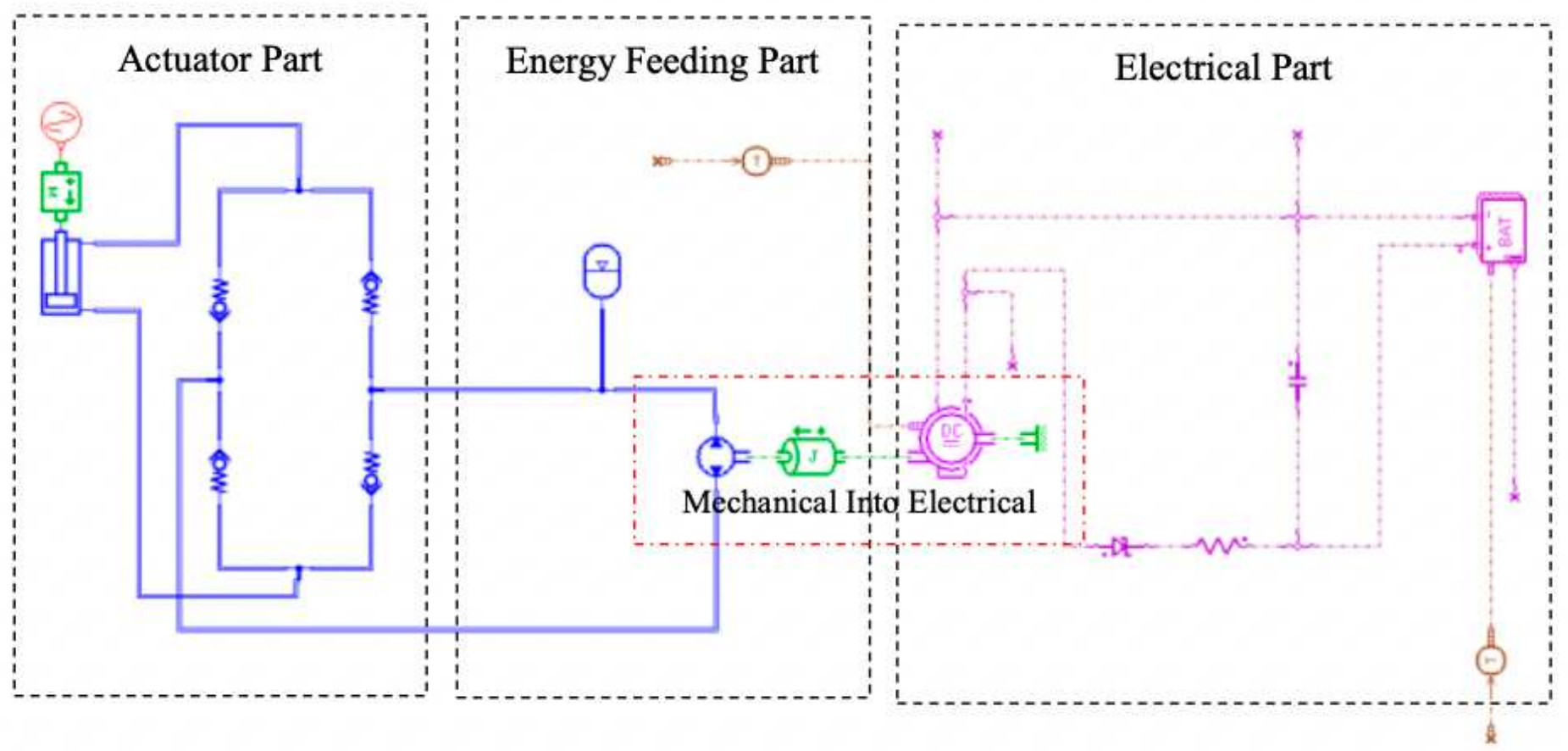

Figure 4

LMS Regenerative Shock absorber Energy Feeding



Figure 5

Double Hydraulic Chamber Single Rod jack Stroke 


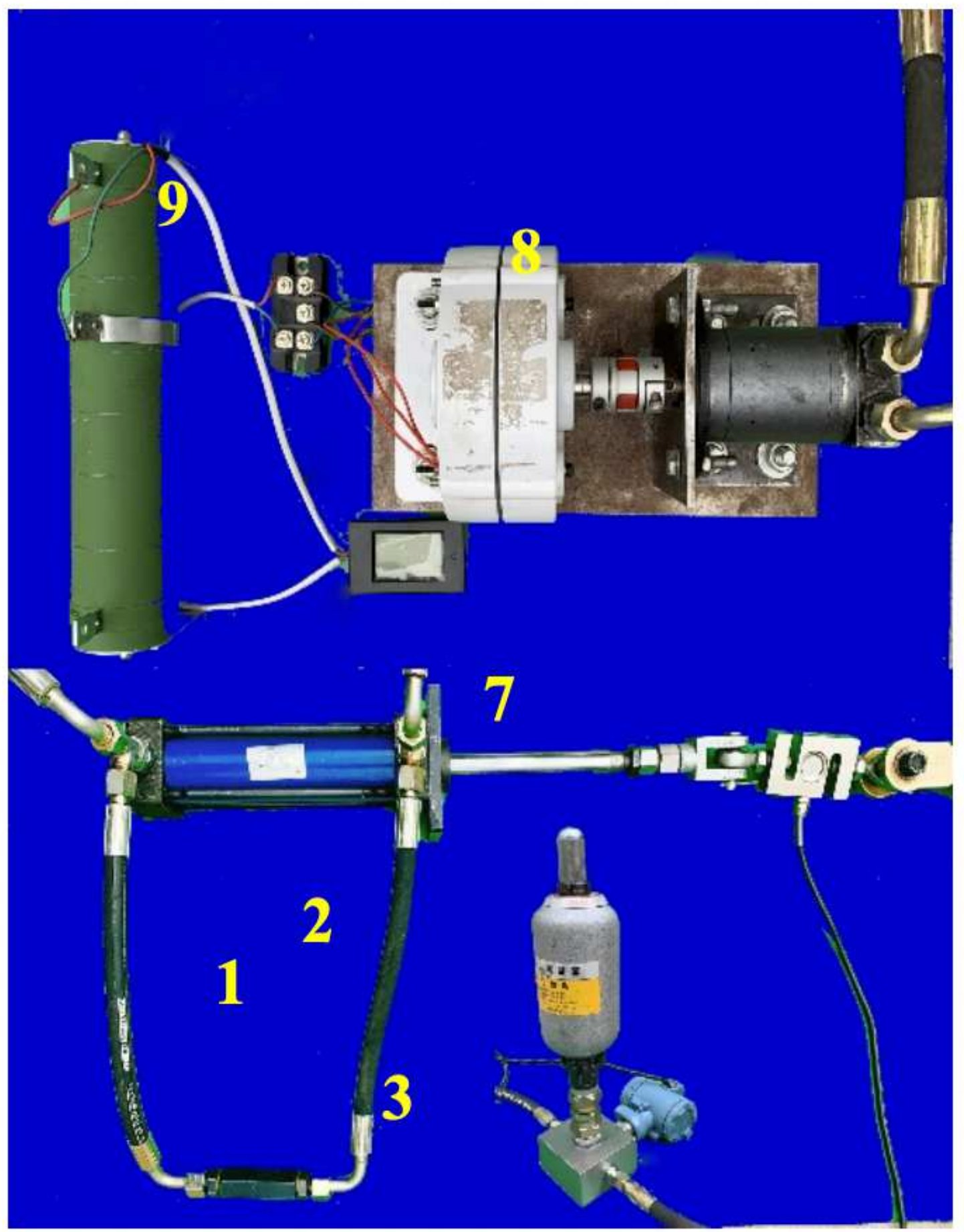

\section{Figure 6}

Prototype of Hydraulic Regenerative shock Absorber (1) Hydraulic cylinder (2) Accumulator (3) Pressure Transducer $(4,6)$ Hydraulic Rectifier (5) Hose (7) Force Transducer (8) Hydraulic Motor (9) Three Phase alternator (10) Sliding Rheostat 


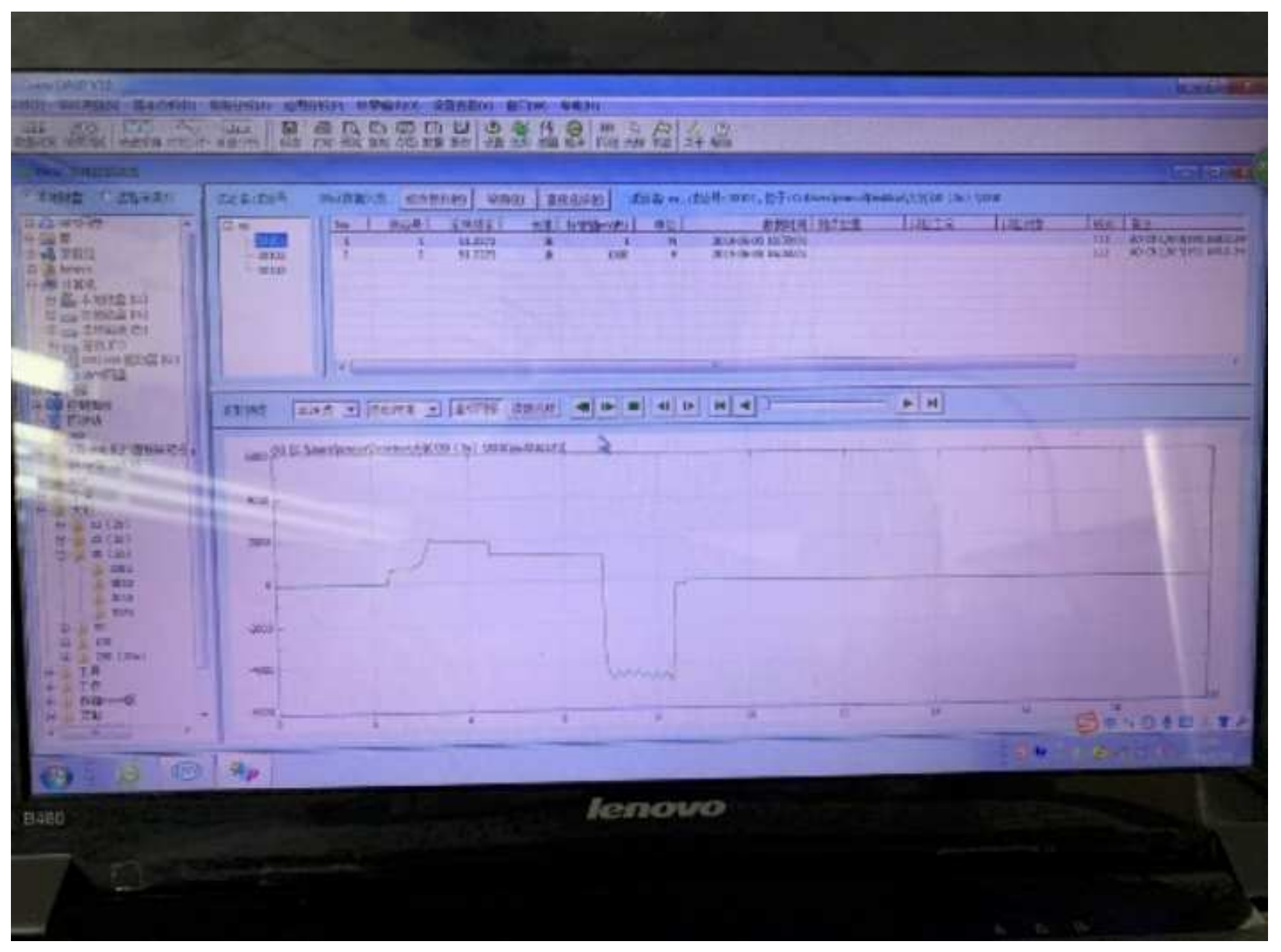

Figure 7

Data Acquisition

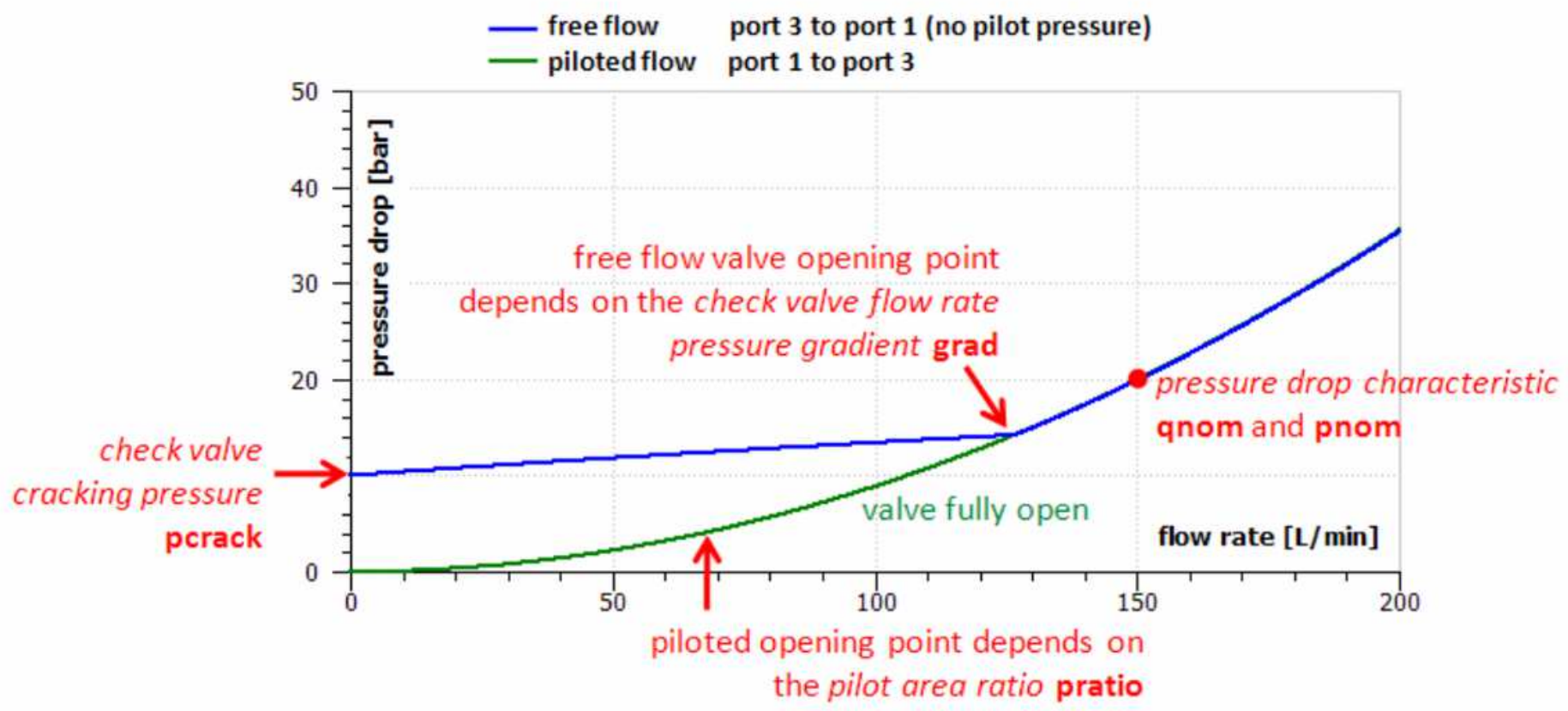


Figure 8

Hydraulic Check Valve Pressure Flow rate Curves
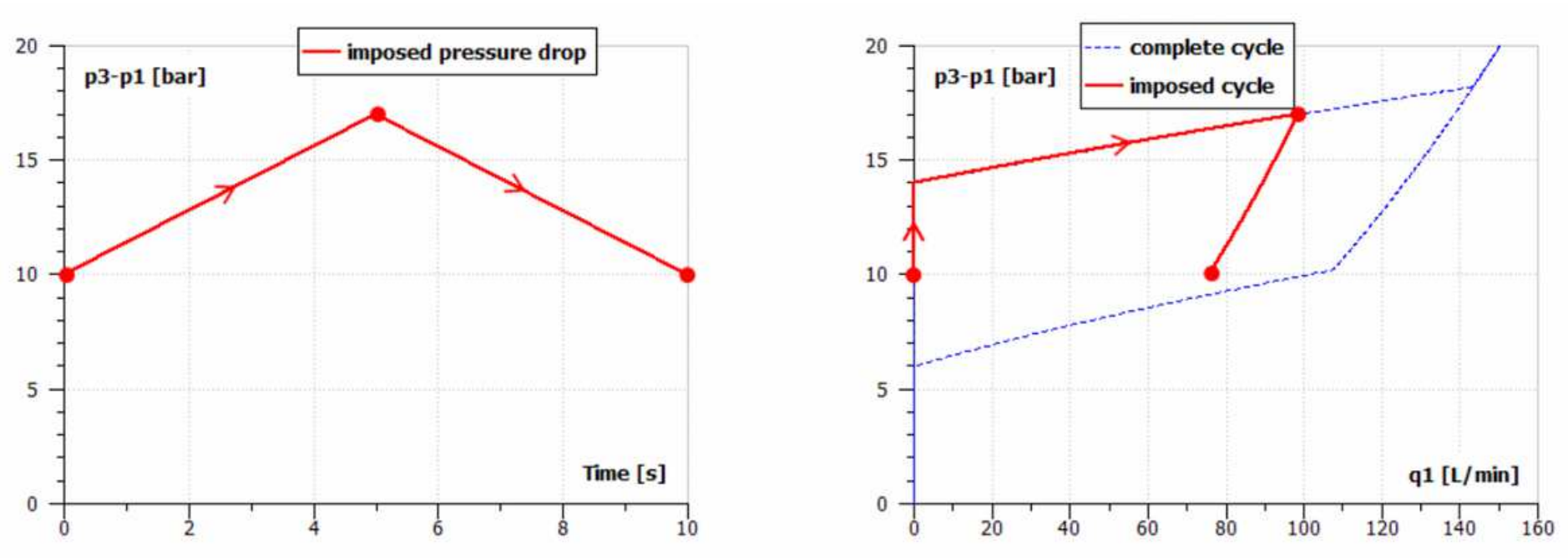

Figure 9

Hysteresis behavior of Hydraulic Rectifier

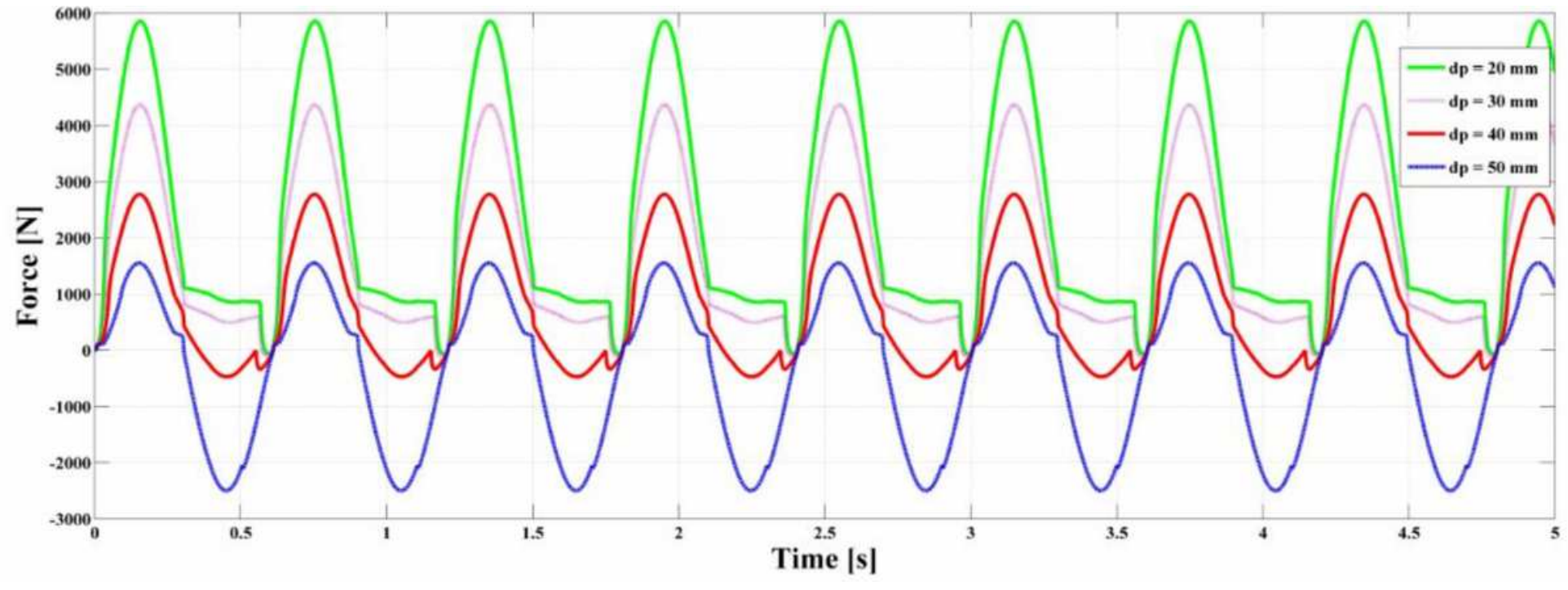

Figure 10

Piston Body Force at different piston diameter 


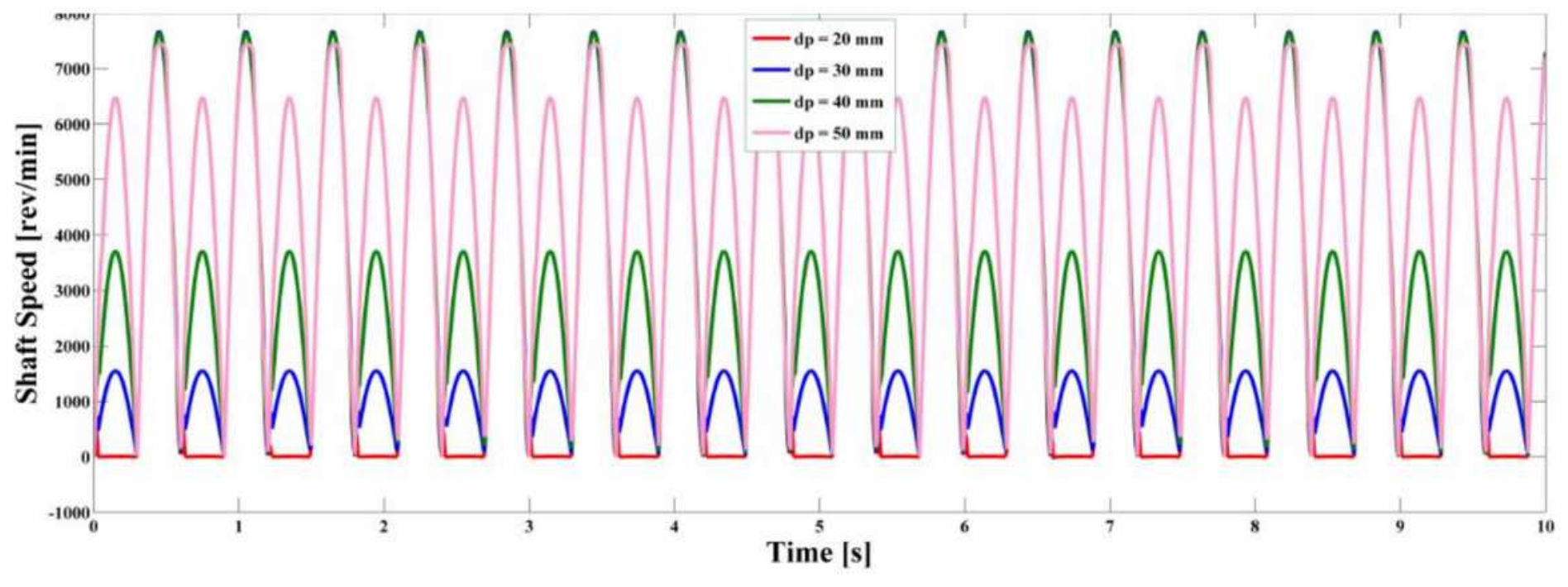

Figure 11

Shaft Speed at different Piston Diameter

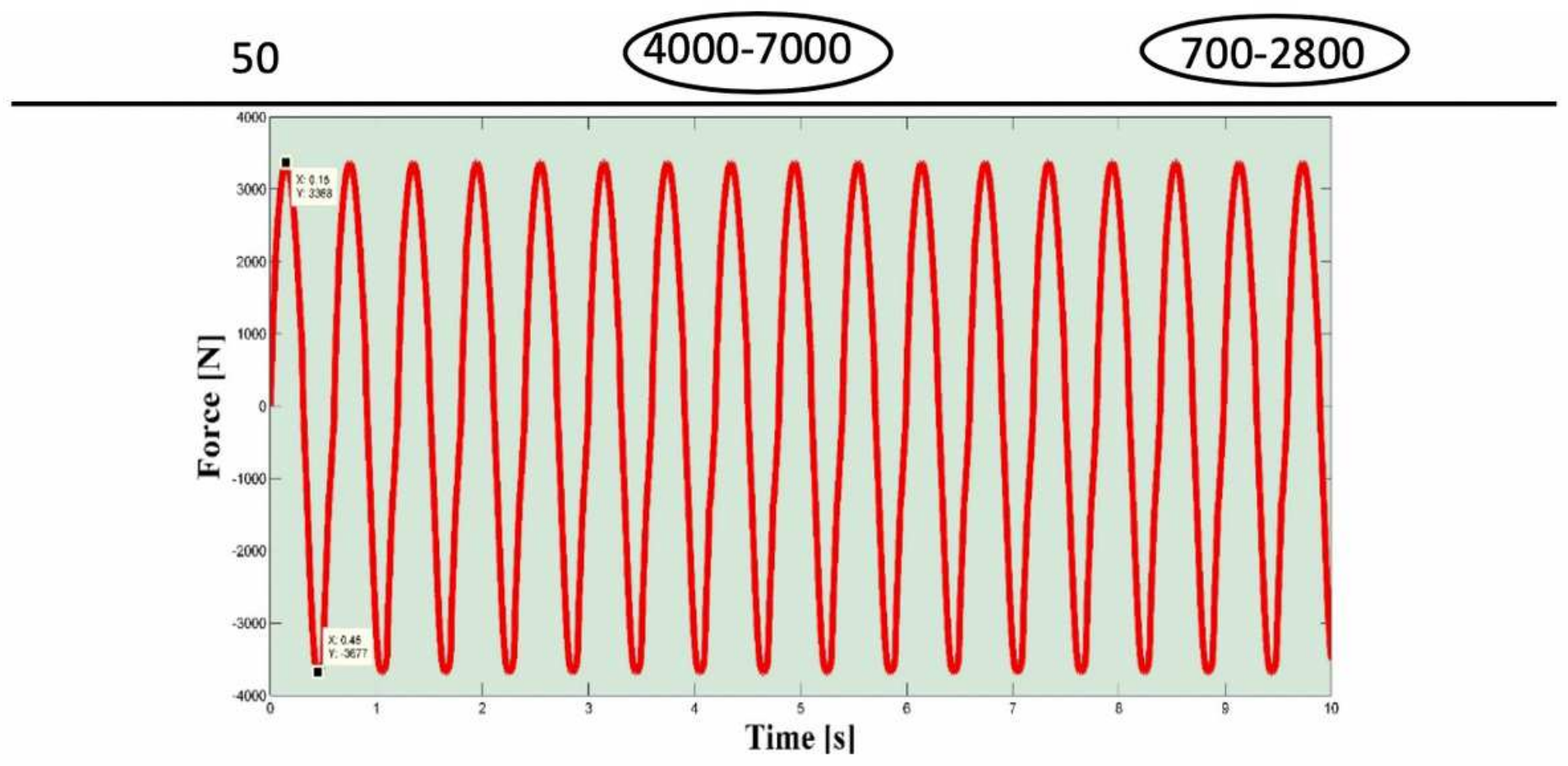

Figure 12

Force Energy Ratio Curves 


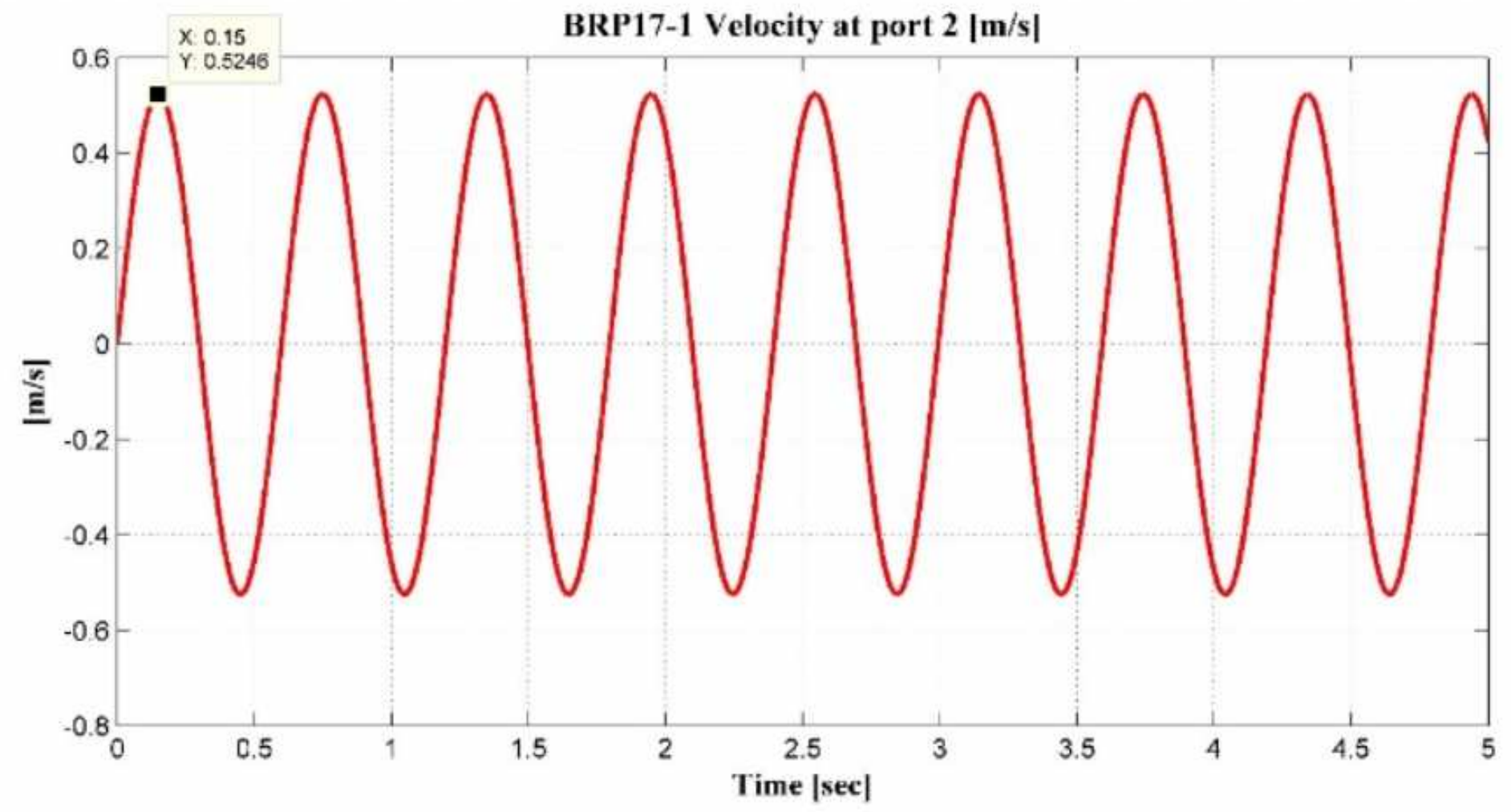

Figure 13

Velocity of advanced hydraulic regenerative shock absorber

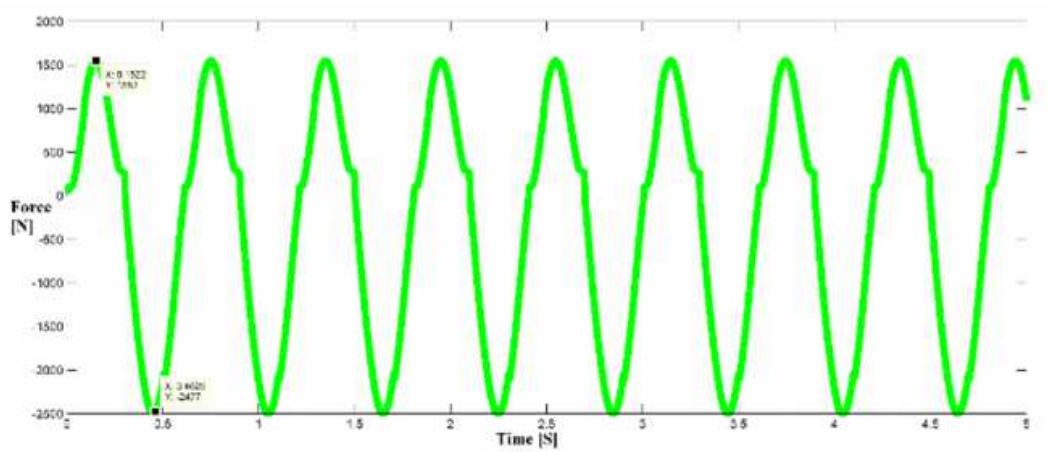

(a)

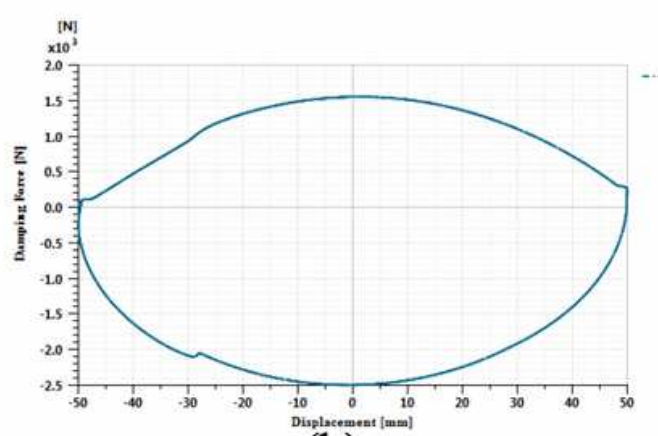

(b)

Figure 14

(a)Damping Piston Force; (b) Damping Characteristics Curves 


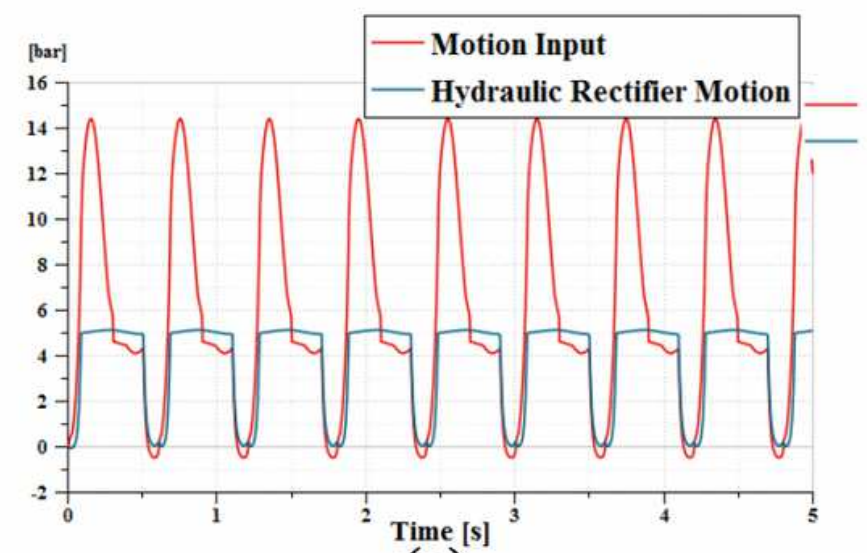

(a)

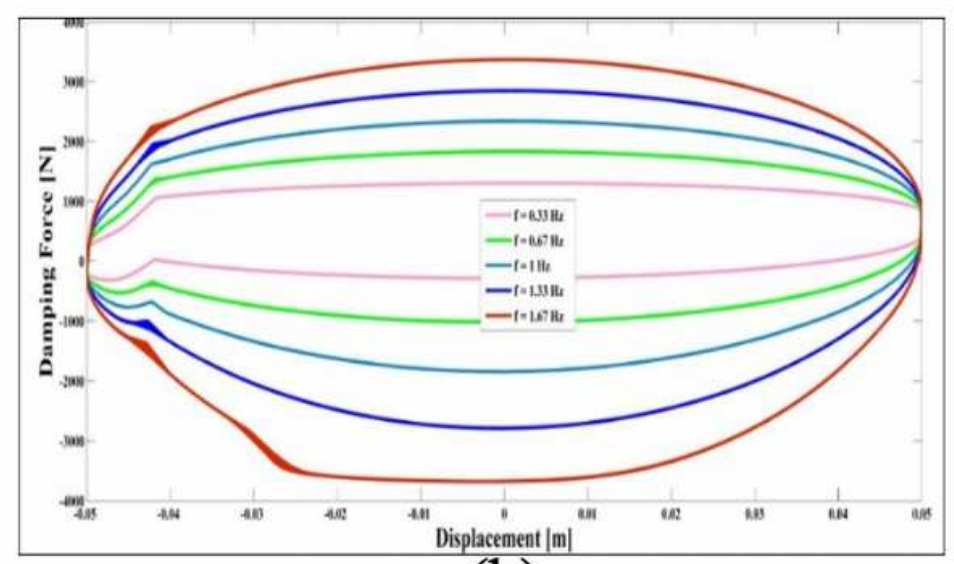

(b)

Figure 15

(a) Hydraulic Rectified Motion Curves; (b) Damping Characteristics Curves at different frequency

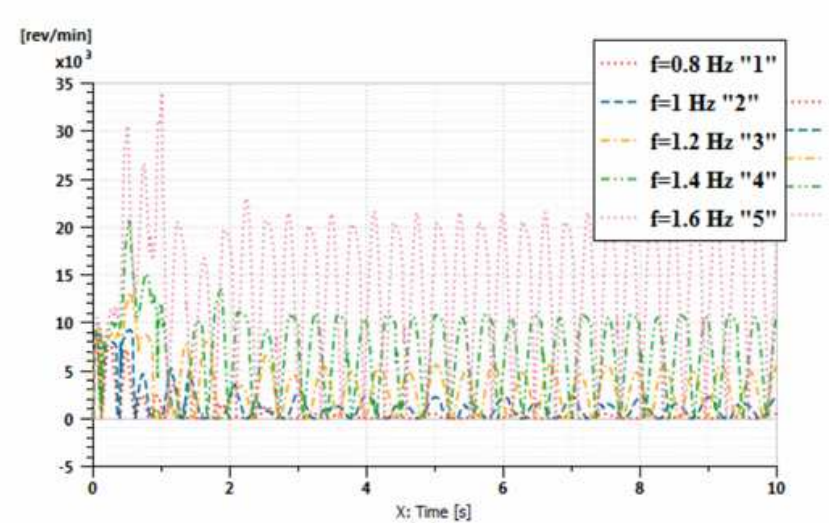

(a)

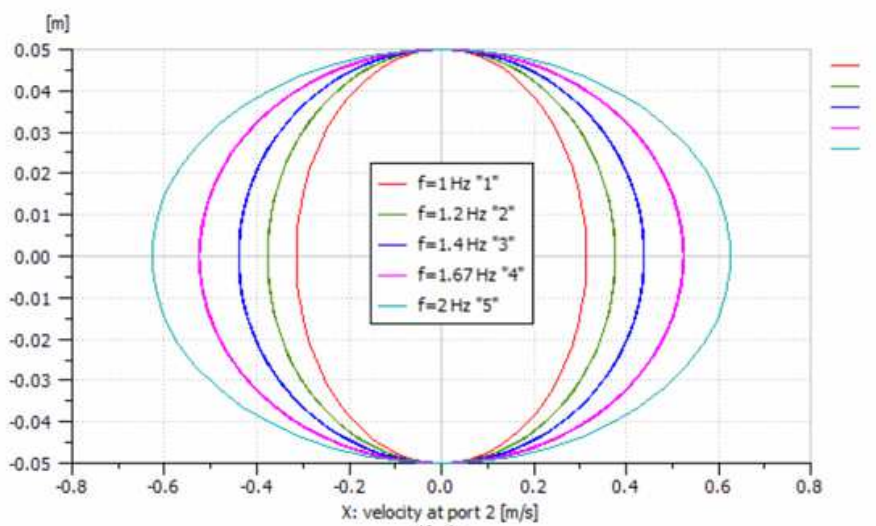

(b)

\section{Figure 16}

(a) Shaft Speed; (b)Velocity Displacement Curves at Different frequency Curves at different frequency 


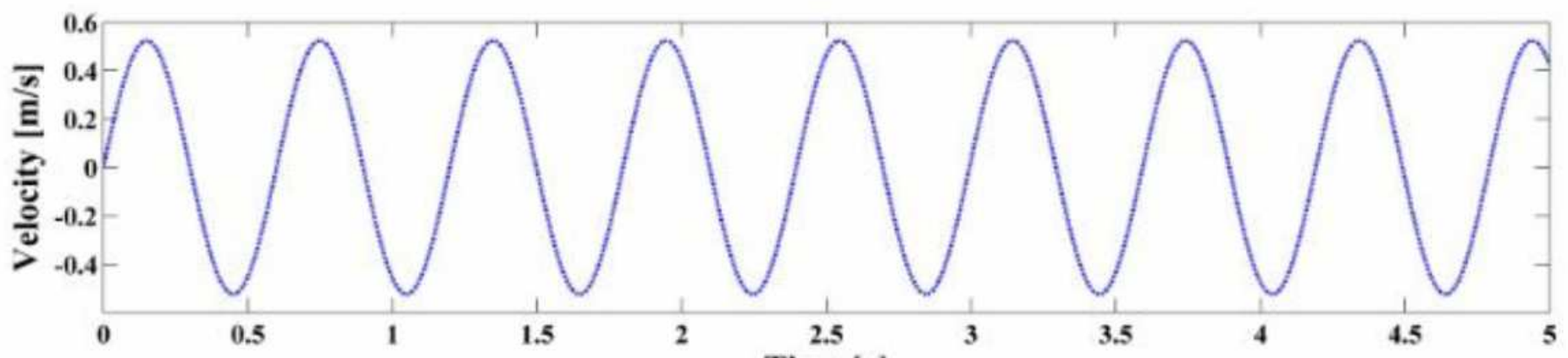

Time [s]
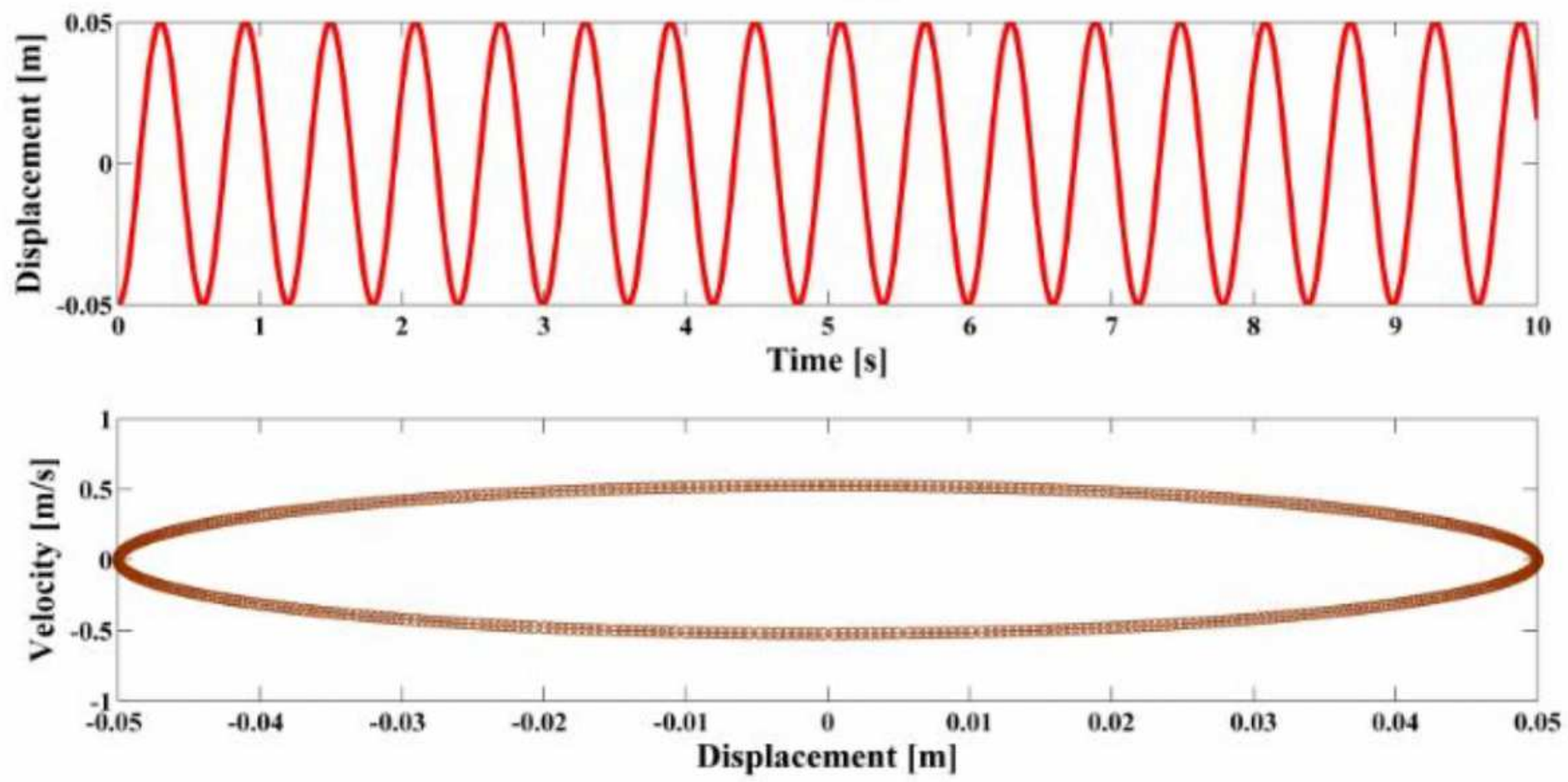

Figure 17

Velocity and Displacement of the moving piston body Curves

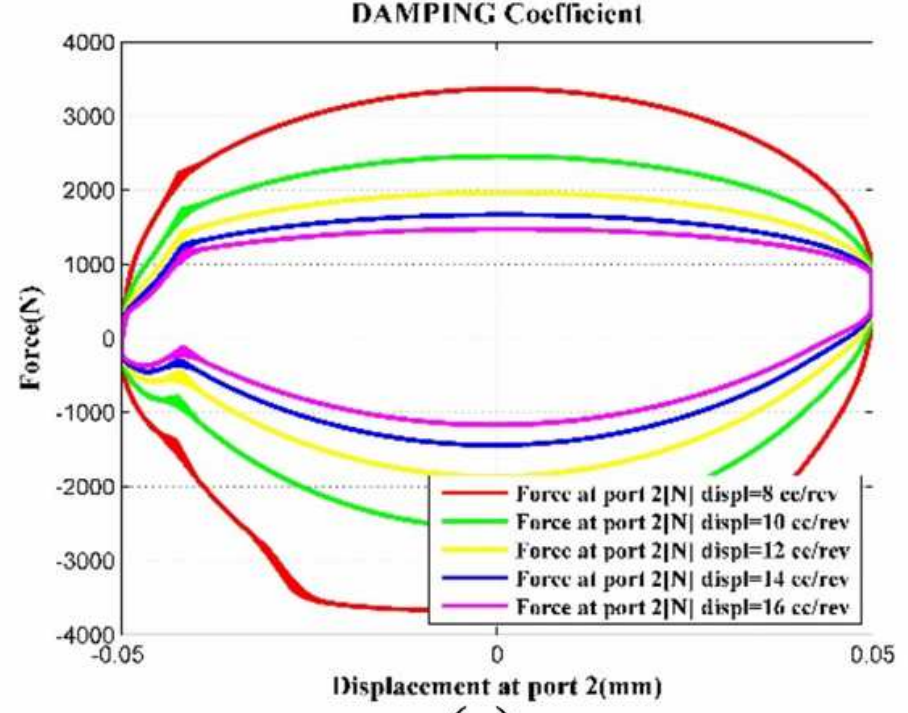

(a)

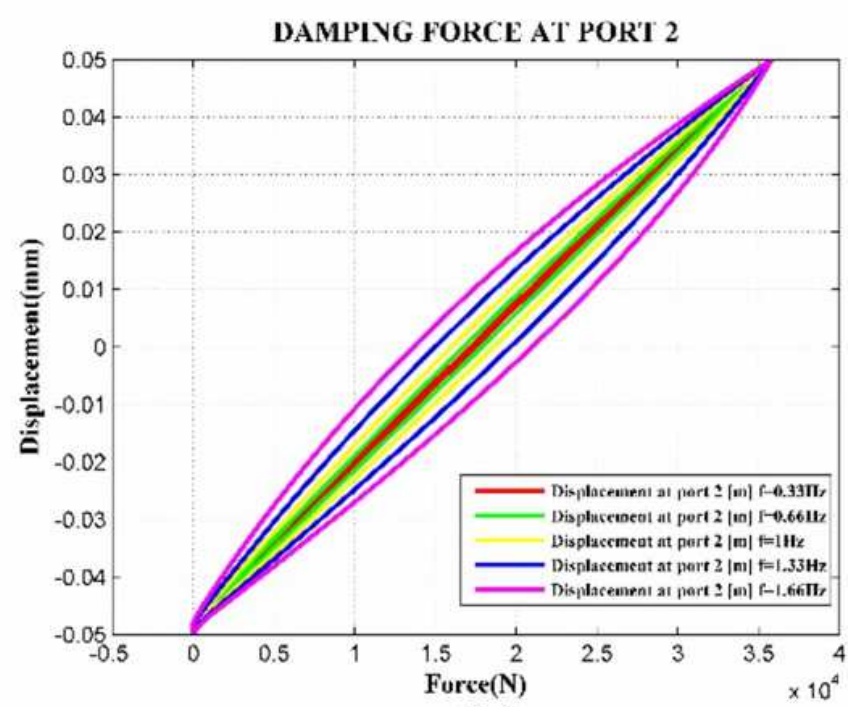

(b) 
Figure 18

(a) Damping force at different displacement; (b) Damping force at different Sinosidal Frequency 